\title{
Topologies and Operation Modes of Rail Power Conditioners in AC Traction Grids: Review and Comprehensive Comparison
}

\author{
Mohamed Tanta ${ }^{1, *(\mathbb{D}}$, José Gabriel Pinto ${ }^{1}\left(\mathbb{D}\right.$, Vitor Monteiro ${ }^{1}\left(\mathbb{D}\right.$, Antonio P. Martins ${ }^{2}{ }^{(0)}$, \\ Adriano S. Carvalho ${ }^{2}$ and Joao L. Afonso ${ }^{1}$ (D) \\ 1 Department of Industrial Electronics, University of Minho, Campus of Azurém, 4800-058 Guimarães, \\ Portugal; gpinto@dei.uminho.pt (J.G.P.); vmonteiro@dei.uminho.pt (V.M.); jla@dei.uminho.pt (J.L.A.) \\ 2 Faculty of Engineering, University of Porto, Rua Roberto Frias, 4200-465 Porto, Portugal; \\ ajm@fe.up.pt (A.P.M.); asc@fe.up.pt (A.S.C.) \\ * Correspondence: mtanta@dei.uminho.pt; Tel.: +351-253-510-190
}

Received: 31 March 2020; Accepted: 19 April 2020; Published: 1 May 2020

check for updates

\begin{abstract}
Electric locomotives in AC traction power systems represent a huge single-phase non-linear load and, detrimentally, affect the power quality and the efficiency of the three-phase power grid. Nevertheless, along the last decades, power electronics are being used to mitigate power quality problems in the three-phase power grid. In particular, Rail Power Conditioner (RPC) helps to increase the loading capacity of traction substations and improve the power quality of three-phase power grids. As the main characteristics, an RPC can supply reactive power, suppress current harmonics and overcome currents imbalance of the three-phase power grid. On the other hand, the traction substations may be constituted by different types of power transformers. For instance, single-phase power transformers and open-delta $(\mathrm{V} / \mathrm{V})$ power transformers are widely used, while Scott power transformers are less frequently used, since they are more complex and expensive. In this framework, this work presents a review study of RPC topologies, including their operation modes, and a comprehensive comparison between the characteristics of the RPC topologies when using different types of AC traction substations and power transformers. This helps to ensure the correct selection of the RPC topology for a specific application, according to the main structure of the traction substation. Consequently, and based on the established review, it is possible to sort and allocate each RPC topology for limited or wider applications.
\end{abstract}

Keywords: power quality; rail power conditioner; Scott power transformer; traction power grid; $\mathrm{V} / \mathrm{V}$ power transformer

\section{Introduction}

In recent years, high-speed electrified railway has reached a rapid development and has been considered as one of the economic booster indicators, granting the most secure land transportation mode in terms of freight and passenger transport [1]. However, and unfortunately, many power quality problems are caused by electric trains. This is due to the single-phase traction power grid characteristics in which many single-phase electric locomotives introduce harmonic contents and cause imbalance in the three-phase currents. The power quality deterioration not only affects the single-phase traction power grid, but it also threatens the stability and the safe operation of the three-phase power grid. Therefore, power quality improvement is a significant factor to guarantee the safety and the economical operation of the electric trains [2-4].

In this context, a power compensator installed on two traction feeders of the traction power grid, called, a Rail Power Conditioner (RPC) was introduced in $[5,6]$. In the RPC system, two power 
converters (one for each traction feeder) can act to compensate reactive power, thus providing the reactive power required by the traction loads and maintaining near a unitary power factor of the three-phase power grid. In addition, RPC balances the active power between the two traction feeders. Consequently, balanced three-phase currents with reduced harmonic contents and without negative sequence component (NSC) can be obtained [6-9].

The conventional RPC system presented in Figure 1, is composed of a full-bridge back-to-back (B2B) converter (FB-RPC), which is connected to two traction feeders through two coupling transformers (CTs). These transformers are important to achieve the required galvanic isolation between the RPC and the single-phase traction power grid, besides step-down of the traction feeders voltage [10]. Subsequently, some improved topologies based on the FB-RPC are presented in the literature. For instance, a comprehensive analysis of the FB-RPC system based on an unbalanced open-delta (V/V) power transformer, providing simulation and experimental results, is presented in [6]. An RPC system, based on V/V power transformer and equipped with an energy storage system, is presented in [11], which uses a supercapacitor that is connected to the DC-link of the RPC via a bidirectional DC-DC converter. This energy storage system is useful for reducing the peak power demand and the operation costs in a railway substation. In [12], an improved grid voltage sensorless control strategy for the RPC system is proposed to replace the AC voltage sensors by a virtual flux method based on second-order low-pass filters.

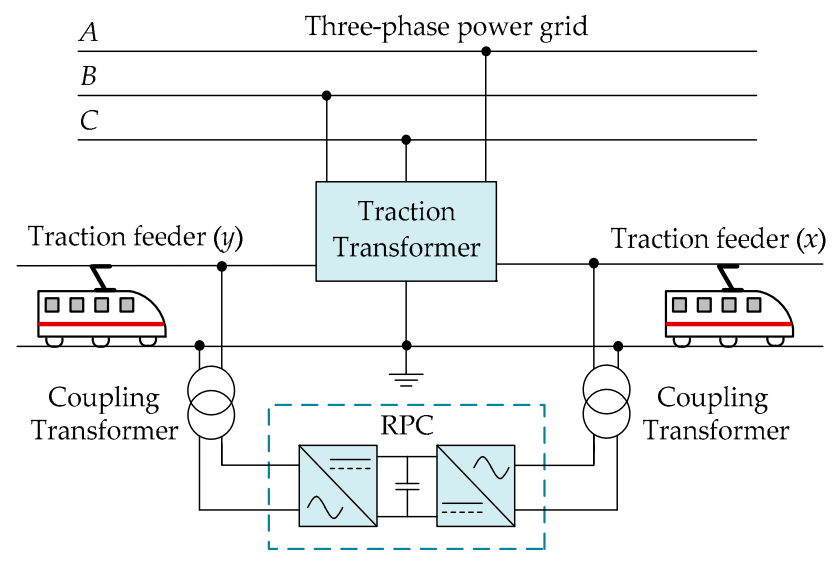

Figure 1. FB-RPC system linked to a single-phase traction power grid (based on [6]).

The imbalance ratio of the three-phase currents depends on the topology of the traction systems, as well as the type of power transformer [13]. When a traction system contains a balanced power transformer (such as Scott, LeBlanc, YNvd, Woodbridge, and the impedance-matching transformers), the two-phase balanced secondary currents will result in balanced three-phase primary currents. In this context, the combination between the RPC system and the balanced power transformers is studied in [14-16]. For instance, the combination of an RPC with YNvd transformer for co-phase traction power supply system is studied in [14].

Co-phase hybrid RPC system (co-HRPC), proposed in [16-18], is extensively studied by researchers, in which a partial compensation is adopted to reduce both the current and voltage ratings of the RPC converter. This is possible by using a capacitive-inductive structure in one coupling branch of the RPC, which improves the RPC performance. In [19], a study recommends to include a double asymmetric capacitive-inductive structure in the two coupling branches of the RPC for a better heavy-load compensation capacity with a lower DC-link voltage. On the other hand, a flexible DC-link voltage control for the co-HRPC system is proposed in [20] to reduce the power losses during the RPC operation, besides reducing the RPC ratings. A hybrid RPC (HRPC) system may contain additional power filters to reduce the volume and power ratings of the system. In this context, a combination of RPC and Static Var Compensator (SVC) is presented in [21]; however, a coordinated control is necessary for two subsystems of RPC and SVC [10]. The relationship between the DC-link voltage of the HRPC 
and its power quality compensation capability is presented in [22], where the experimental results show that, the higher is the DC-link voltage of the HRPC, the better is the compensation capability achieved.

Two-phase three-wire RPC (TW-RPC) contains three switch legs, thus allowing to reduce a switch leg when compared with the FB-RPC system [7]. In that regard, hybrid TW-RPC is presented in [23]. In addition to this, in [24], a quasi-Z-source TW-RPC is proposed and, in [25], a Z-source TW-RPC is proposed to decrease the ratings of the RPC converter. In [26], a TW-RPC with an isolation Scott transformer is proposed, which converts the two-phase traction power grid to a nearly balanced three-phase power system; this helps to reduce the RPC power ratings. On the other hand, simplified half-bridge RPC (HB-RPC) only contains two switch legs, thus allowing to reduce two switch legs when compared with the FB-RPC system [8]. A comparative study of the FB-RPC, TW-RPC, and HB-RPC is presented in $[27,28]$.

RPC based on indirect AC/DC/AC Modular Multilevel Converter (MMC) and half-bridge submodule (SM) topologies has recently been proposed due to the MMC advantages, such as scalability, lower harmonics production, lower voltage stress, and lower switching losses [13]. In this context, RPC based on two full-bridge B2B single-phase indirect MMC (HB-MMC4 RPC) and a V/V power transformer is presented in [29]. In addition, a study of the HB-MMC4 RPC and a Scott power transformer is presented in [15]. Other studies discuss the RPC based on two-phase three-wire indirect MMC (HB-MMC3 RPC) as a prominent solution in a V/V traction power system due to the lower costs and the high compensation capacity. In this framework, a combination of a hybrid HB-MMC3 RPC and a V/V power transformer is presented in [30]. In addition, in [10], the HB-MMC3 RPC in V/V and Scott power transformers is studied. In [31], the RPC based on the half-bridge indirect MMC (HB-MMC2 $\mathrm{RPC}$ ) and V/V power transformer is investigated. In [32], a hybrid HB-MMC2 RPC and a single-phase power transformer is discussed. On the other hand, RPC based on direct AC/AC MMC and full-bridge SM (FB-MMC2 RPC) topology has recently been proposed by researchers. Accordingly, in [33], the FB-MMC2 RPC in V/V and Scott power transformers is presented, while, in [34], an evaluation for the RPC based on delta-connected direct AC/AC MMC with full-bridge SM is presented.

The MMC topology is not the only solution to reduce the voltage and the frequency stress of the RPC switching devices. In this context, modular full-bridge B2B RPC topologies (MRPC) are presented in [35-37], in which each RPC module can be treated as an independent FB-RPC. MRPC system for power quality compensation in co-phase traction power supply system is studied in [37]. The use of MRPC is more common, since a single FB-RPC cannot withstand the high values of currents and voltages. On the other hand, the MRPC solution and its management control strategy with renewable energy access is presented in [38], showing a better integration of the distributed renewable energy sources along the railway, besides the power quality control of the railway system.

Figure 2 shows a main classification of the RPC topologies. The two-level RPC category consists of a single two-level converter with a limited number of switching devices. The multilevel RPC category, presented in this paper, is mainly based on the MMC, and the multiple RPC category is considered when many two-level RPC modules can be processed independently due to the isolation of the multiple secondary windings transformer. Among these topologies, based on different power converters and traction systems, advantages and disadvantages can be identified, as well as differences between the RPC topologies. Therefore, a key question is: What are the best and most adequate conditions for each topology to operate and when can be effectively utilized? In that respect, no articles in the published studies present a comprehensive review of the RPC topologies, including the RPC operation modes as well. Consequently, the main contribution of this paper is to present a review of the most relevant RPC topologies, presenting a comparative study that includes the main similarities and differences of these topologies. In addition, the RPC operation modes are explained in the paper.

This paper is organized as follows. Section 2 explains the RPC operation modes. Section 3 presents a comprehensive study of the most relevant RPC topologies. Section 4 presents a comparative study between the RPC topologies in the V/V and Scott traction power systems. Finally, Section 5 summarizes the main conclusions of the paper. 


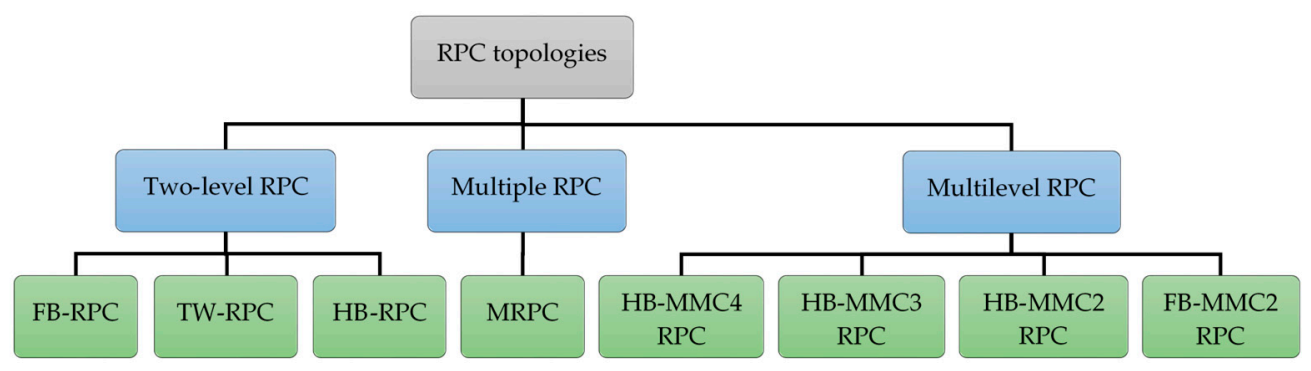

Figure 2. Classification of the RPC topologies (based on $[6-8,10]$ ).

\section{RPC Feeding Substation: Operation Modes}

The key feature of the RPC topology is the potential of different operation modes, in which each operation mode can be implemented by using the same converter hardware, but the converter control is quite different. The operation modes can be implemented either to increase the power capacity of the traction substation or to solve one or more of the power quality problems. When the two terminals of the RPC are connected to a single-phase traction power grid, the RPC can operate as an SVC. On the other hand, when the two terminals of the RPC are connected to two-phase traction power grid, the RPC can transfer active power between the two-phases [39].

\subsection{Static Var Compensator}

Normally, the power transformers, such as the V/V and Scott, are constituted by a three-phase input and a two-phase output. When one of the traction transformer output phases is disconnected due to periodic maintenance, in this case, the SVC mode based on a single-phase power transformer is implemented, as shown in Figure 3 Accordingly, the active power cannot be shifted between the traction feeders, and the RPC operates as an SVC system only to compensate reactive power and harmonic distortion, as presented in Table 1. The RPC based on SVC mode calculates the reactive power of the substation according to the traction feeder currents and voltage deviation, and then the converter controls the reactive power that has a reverse polarity of the calculated reactive power to accomplish reactive power compensation. The converter $x$ and converter $y$ are connected in parallel, and, therefore, each converter injects half of the reactive power amount $[40,41]$.

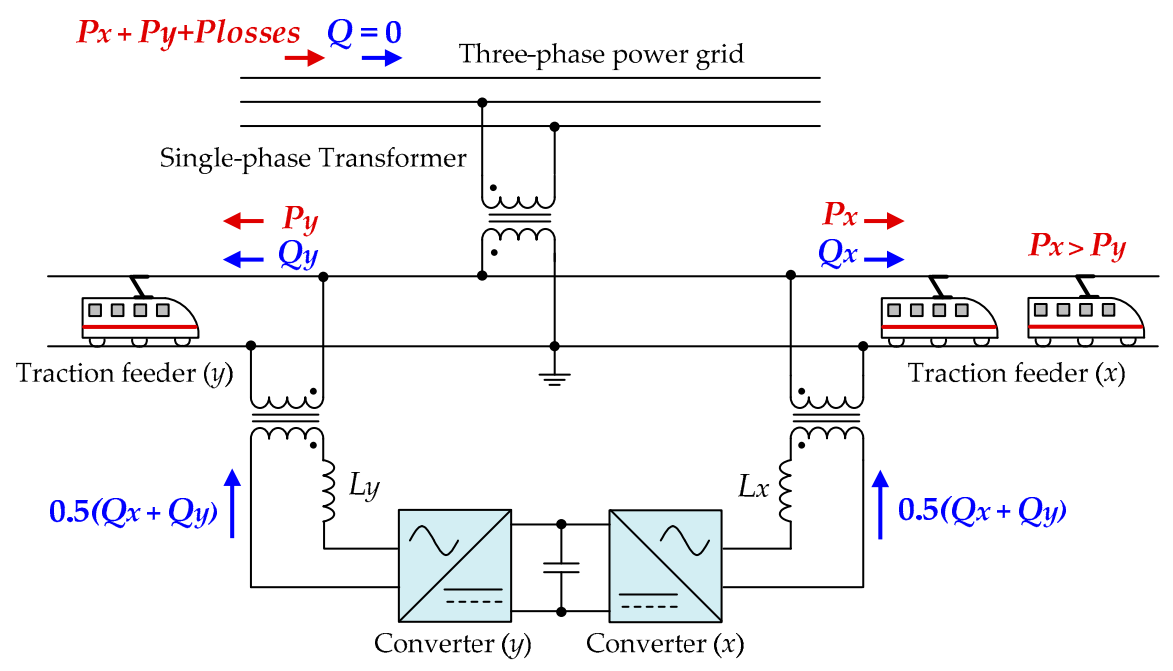

Figure 3. RPC operating in SVC mode (RPC based SVC) (based on [40]).

Table 1. Capabilities of RPC operating in SVC mode. 


\subsection{Catenary Voltage Regulator}

An additional operation mode is implemented when the RPC is not directly connected to the traction substation, but it is connected to a certain zone of the overhead catenary line, as shown in Figure 4. In that case, no active power shifting or reactive power compensation is applied. However, the converter, in this case, can produce reactive power to compensate the feeding voltage drop caused by the loads of the traction feeders, as presented in Table 2. The voltage regulation in the overhead catenary lines occurs due to the internal impedance of the line. On the other hand, this operation mode overcomes the effect of the three-phase power grid voltage oscillations to maintain constant overhead catenary voltages. The catenary voltage adjustment near the connection point is achieved by controlling the reactive power output $Q_{x}, Q_{y}[9,40]$.

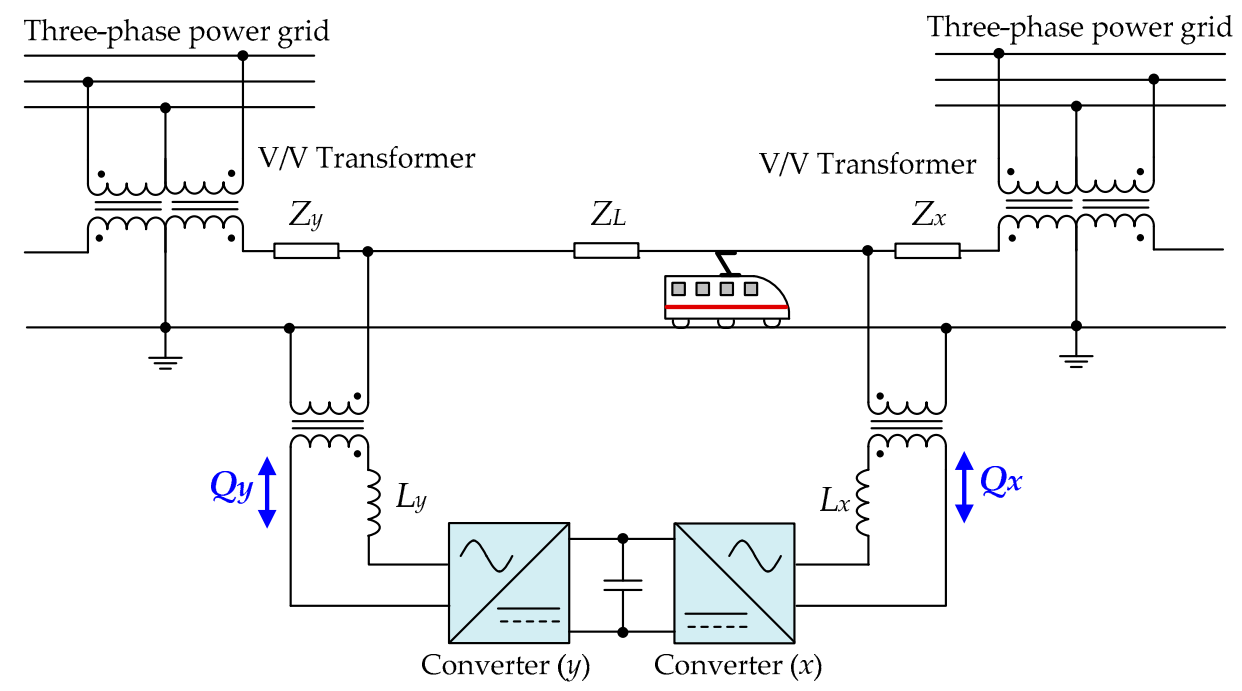

Figure 4. RPC operating in catenary voltage regulator mode (based on [40]).

Table 2. Capabilities of the RPC operating in catenary voltage regulator mode.

\begin{tabular}{|c|c|c|c|}
\hline Active Power Shifting & Reactive Power Compensation & Harmonics Cancelation & Catenary Voltage Stability \\
\hline$x$ & $\times$ & $\times$ & $\checkmark$ \\
\hline
\end{tabular}

\subsection{Interface Converter between Two Collateral Substations}

One additional operation mode is when the RPC operates as an interface converter between two substations for the double-side feeding system, as shown in Figure 5. In this case, it is used as an interface between two-phases (with different phase-angles) and the control is quite different from the conventional application of the RPC. The RPC for this application is mainly used for the purpose of power transfer, by controlling the interface converter, as a voltage source or as a current source, to extract power from two substations instead of only one substation. By another meaning, it is possible to shift the active power from one substation to another, aiming to increase the power capacity of the traction substation. In addition, this solution has no ability to compensate NSC of currents, thus the three-phase currents may suffer from imbalance [42]. Table 3 presents the main capabilities of this solution. 


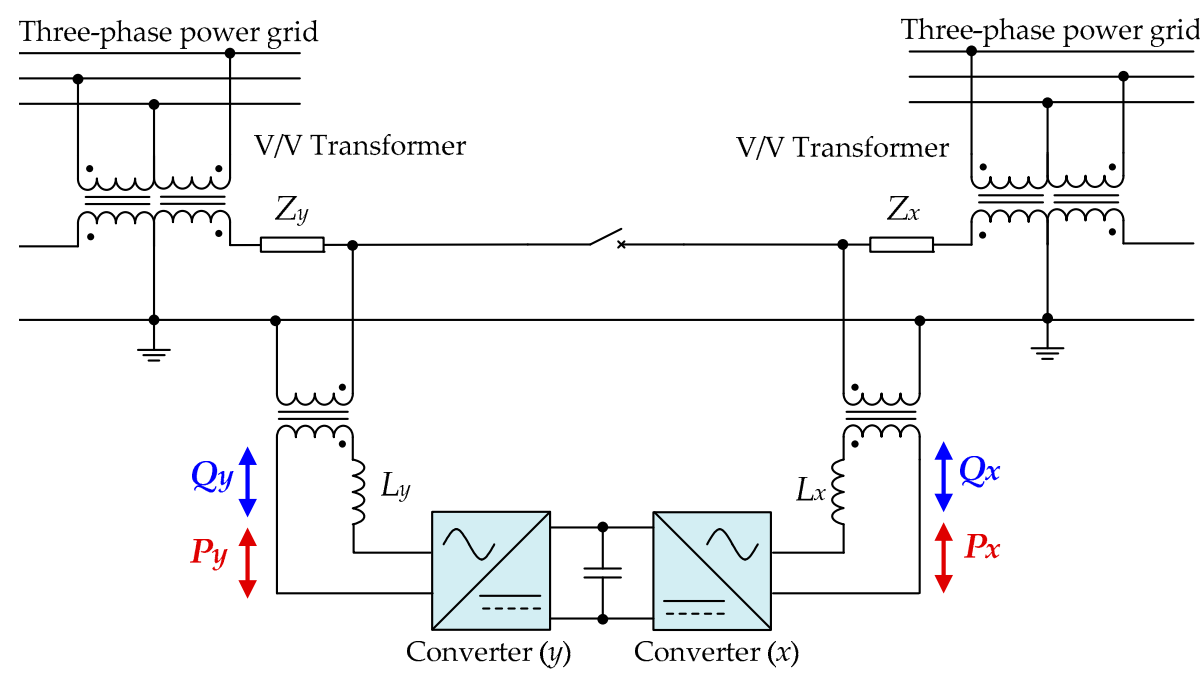

Figure 5. RPC operating as an interface converter between two substations (based on [42]).

Table 3. Capabilities of the RPC operating as an interface converter between two substations.

\begin{tabular}{|c|c|c|c|}
\hline Active Power Shifting & Reactive Power Compensation & Harmonics Cancelation & Catenary Voltage Stability \\
\hline$\checkmark$ & $\times$ & $\times$ & $\times$ \\
\hline
\end{tabular}

An RPC interface converter located between two collateral substations is presented in [42], as commercialized by Hitachi, Japan. The system started to operate in 2015 and is designed to shift active power from one substation to another, including the power resulting from the regenerative braking of trains. The RPC converter was manufactured for the $22 \mathrm{kV}$ AC catenary line and installed at the Ushiku neutral section between Tsuchiura and Fujishiro traction substations in Japan. Both traction substations were equipped with arithmetic units that compute the amount of electric power consumed and regenerated. Each of these units transmits the power data to a central control unit of the RPC installed at the neutral section between the traction substations. Digital subscriber line communication technology was used to a range of $10-20 \mathrm{~km}$. The converter was designed with a total capacity around of 2.6 MW. However, since regenerative electric power is frequently generated in large amount over short time duration, the power transformer and cooling system have been adapted by giving the system a 1-min overload capacity of 5.3 MW. A single-phase full-bridge power converter using Insulated-Gate Bipolar Transistor (IGBT) switching devices was used, with a total DC-link of $6 \mathrm{kV}$.

\subsection{Rail Power Conditioner}

High-speed trains are single-phase non-linear loads that usually cause NSCs, current harmonics, current imbalance, and low power factor at the three-phase power grid [43]. These power quality phenomena occur regardless of the used power transformers, but the effect of power quality distortion is higher when using unbalanced transformers (V/V power transformers). For instance, to solve the problem of low power factor at the three-phase power grid, reactive power exchange should not be between the traction loads and the three-phase power grid; traction loads have to exchange reactive power with a third party (e.g., power compensator).

RPC systems are very effective in compensating NSC of currents and harmonic contents in the electrified railway. The following RPC schemes are based on the split of the traction power grid into two traction feeders separated by isolators known as catenary neutral sections. RPC systems are designed to tolerate the overloading circumstances that may happen when several locomotives operate at the same traction feeder. The RPC should deal with harmonics compensation, presenting a balanced load, seen by the three-phase power grid point of view, and correcting the three-phase grid power factor to unitary or compensate reactive power. Table 4 presents the capabilities of the RPC operation 
mode. Figure 6 shows the basic principle of operation of the RPC when both traction feeders $(x$ and $y)$ are unequally loaded $\left(P_{x}>P_{y}\right)$ and when using a V/V power transformer. In this case, the RPC system shifts half of the active power difference $\left(P_{C}\right)$ from the highly loaded section (section $x$ ) to the lightly loaded one (section $y$ ).

Table 4. Capabilities of the RPC operation mode.

\begin{tabular}{|c|c|c|c|}
\hline Active Power Shifting & Reactive Power Compensation & Harmonics Cancelation & Catenary Voltage Stability \\
\hline$\checkmark$ & $\checkmark$ & $\checkmark$ & $\times$ \\
\hline
\end{tabular}

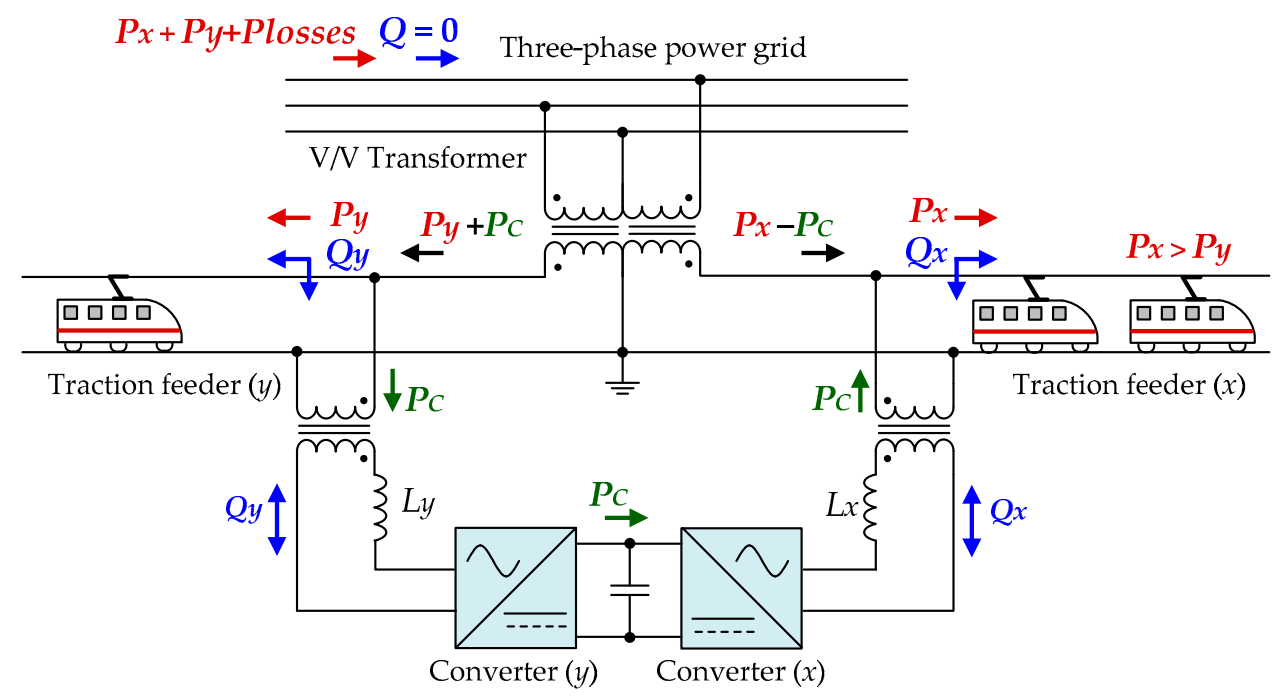

Figure 6. Operation principle of the RPC system (based on [44]).

The power factor of the three-phase power grid is almost unitary since the required reactive power for both load sections is always provided by the RPC compensator. The reactive power exchanged between the single-phase traction power grid and the RPC is bidirectional according to the load conditions and the used power transformer to interface between the three-phase power grid and the single-phase traction grid. For instance, when using the RPC in the V/V connection, the converter $x$ compensates a capacitive reactive power, while the converter $y$ compensates an inductive reactive power, as demonstrated in [31]. The validation of RPC systems in Shin-Numakunai substation in Japan, besides some technical aspects, is presented in [45].

\section{RPC Topologies}

\subsection{RPC Based on a Full-Bridge Back-to-Back Two-Level Converter (FB-RPC)}

The principle of operation of this RPC topology has been described and validated to compensate, simultaneously, NSC, reactive power and harmonic currents $[43,46]$. To overcome the power quality deterioration at the three-phase power grid, RPC based on a full-bridge B2B two-level converter (FB-RPC), sharing the same DC-link, can provide power quality improvement. FB-RPC consists of eight switching devices (IGBTs and freewheeling diodes). The amount of NSC depends on the traction power system topology, particularly the type of the used power transformer. Figure 7 depicts the FB-RPC system. The three-phase line-to-line voltages are stepped-down through a power transformer; then, two isolated traction feeders are acquired. It is assumed that the right traction feeder is called phase $x$, and the left traction feeder is called phase $y$. Since two of the RPC legs are connected to the same grounding point (the rail), two CTs are necessary to avoid short circuits in the RPC. In addition, and by considering the maximum voltage blocking power of $6.5 \mathrm{kV}$ of the commercially available 
IGBTs [47], the CTs are important to step-down the catenary medium-voltage value to a low-voltage value. Table 5 presents the components quantities of the FB-RPC.

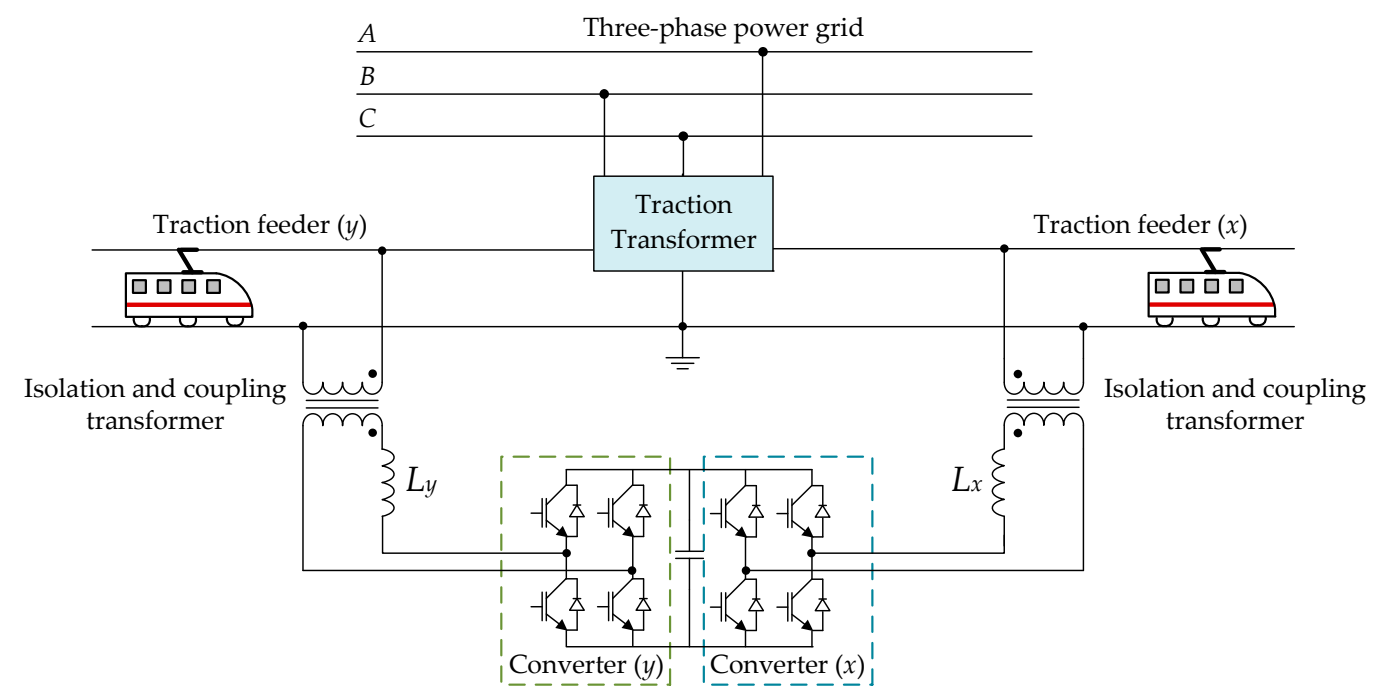

Figure 7. RPC based on a full-bridge back-to-back two-level converter (FB-RPC) with coupling transformers (based on [27]).

Table 5. Components quantities of the FB-RPC.

\begin{tabular}{|c|c|c|c|}
\hline Number of IGBTs & Number of Capacitors & Number of Inductors & Isolation/Coupling Transformer \\
\hline 8 & 1 & 2 & 2 \\
\hline
\end{tabular}

The rapid growth in the railway industry demands finding new technologies to cope with the new requirements of railway electrification. In this context, FB-RPC was a good choice to deal with power quality deterioration caused by electric locomotives. In this topology, the voltage stress of each IGBT is half the DC-link voltage of the FB-RPC. However, the current stress is very high due to the use of step-down CTs. In the FB-RPC, the outer legs generate the compensation currents for phase $x$ and phase $y$, respectively. On the other hand, the two inner legs together generate the compensation current of the common ground. Therefore, the outer legs IGBTs are the most stressed (this is true when removing the coupling transformers) [28]. Normally, the size of power electronic switches is designed to be half of the maximum active power of each section [2], which means that FB-RPC will have eight bulky power electronic switches, a huge cooling system, and high costs.

\subsection{RPC Based on Two-Phase Three-Wire Converter (TW-RPC)}

This RPC system consists of two-phase three-wire converter (TW-RPC), which is fed by single-phase step-down CTs connected to the traction feeders of the traction power grid. Therefore, it can be considered as two single-phase merged converters, sharing the same DC-link voltage, as shown in Figure 8. This generation of RPC compensators has been described and validated to compensating NSC and harmonic currents $[7,26]$. Since each leg of the TW-RPC is connected to different phase or wire, it is not essential to have isolation transformers (ITs) between the converter and the traction feeders as in the case of the FB-RPC. However, step-down CTs are indispensable in this topology [28]. Table 6 presents the components quantities of the TW-RPC. 


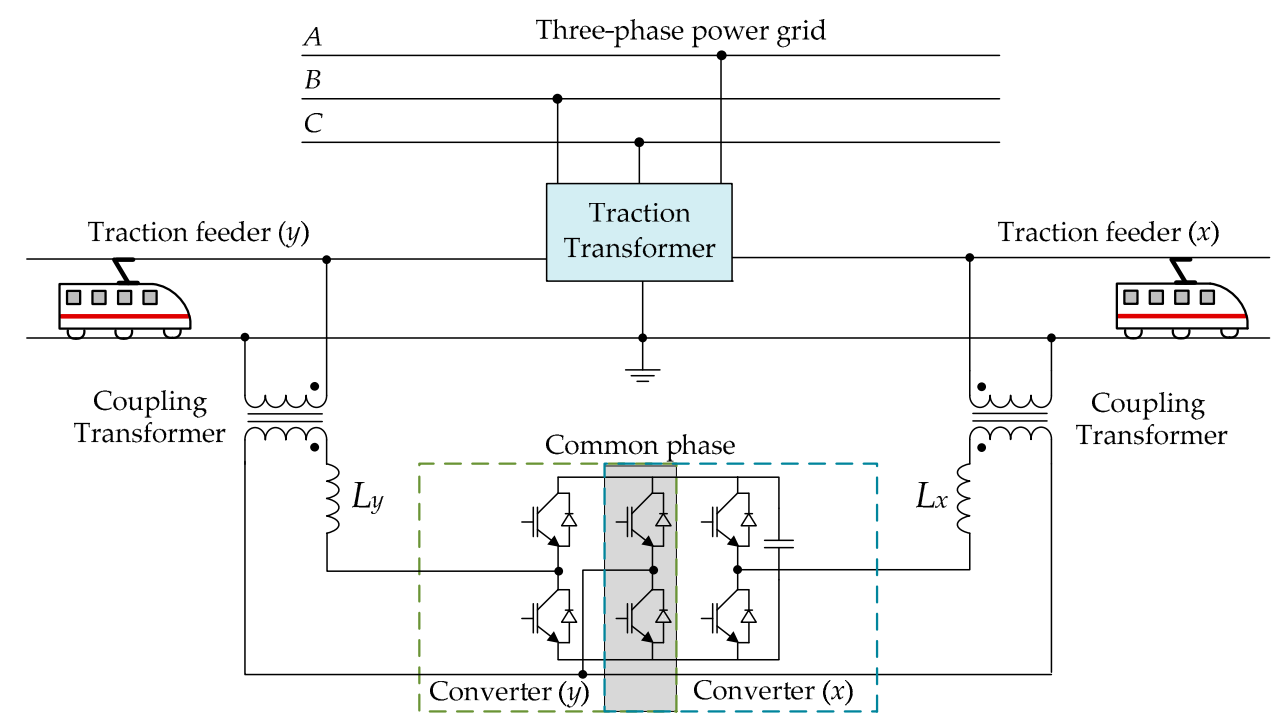

Figure 8. RPC based on two-phase three-wire converter (TW-RPC) with coupling transformers (based on [27]).

Table 6. Components quantities of the TW-RPC.

\begin{tabular}{|c|c|c|c|}
\hline Number of IGBTs & Number of Capacitors & Number of Inductors & Isolation/Coupling Transformer \\
\hline 6 & 1 & 2 & 2 \\
\hline
\end{tabular}

There are six switching devices and one of the TW-RPC wires (the common phase) is connected to the grounded wire or the rail of the two single-phase traction feeders. Hence, a leg with two switching devices is reduced when compared to the FB-RPC, as shown in Figure 8 TW-RPC has the same characteristics and it does the same as the FB-RPC topology, while the rating of the IGBT switching devices in this solution does not increase [27]. In the TW-RPC, the outer legs generate the compensation currents for phase $x$ and phase $y$, respectively. On the other hand, the inner leg generates the compensation current of the common ground phase. Therefore, all the IGBTs in the TW-RPC topology have homogeneous stress. In some applications, the TW-RPC converter can be connected through three-phase step-down CT to the three-phase power grid instead of the single-phase traction power grid [48]. In that case, the solution is denominated as a shunt active power conditioner, which does not offer the operation modes flexibility that the RPC presents. Due to the use of the three-phase coupling power transformer, the shunt active power conditioner can be bulkier and more expensive than the TW-RPC.

\subsection{Simplified RPC Based on a Half-Bridge Two-Level Converter (HB-RPC)}

This system consists of two half-bridge converters connected by two capacitors with a mid-neutral point (HB-RPC), as presented in Figure 9. This RPC can reduce half of the required switching devices comparing to the FB-RPC, which can decrease the power losses, complexity, and the total costs of the HB-RPC system. However, the voltage stress of each switching device in the HB-RPC is double compared with the FB-RPC and TW-RPC. This determines to use switching devices with a higher voltage stress capability [8]. Table 7 presents the components quantities of the HB-RPC. To have a similar performance of the FB-RPC, TW-RPC, and HB-RPC, and by considering identical filter inductors in these topologies, the switching stress for each switching device in the HB-RPC should be twice the value of the applied switching frequency in the FB-RPC and TW-RPC. Otherwise, a higher value of the filter inductor is required for the HB-RPC because of the high current ripple as a result of the half-bridge schematic. On the other hand, by using a high switching frequency increases the switching losses of the switching devices. The results presented in [8] confirm that HB-RPC has a good performance regarding the power quality improvement in electrified railway, including, NSC and harmonic contents 
compensation. Although the HB-RPC has some drawbacks, as previously indicated, it provides one of the attempts to accomplish power quality improvement in the high-speed electrified railway systems.

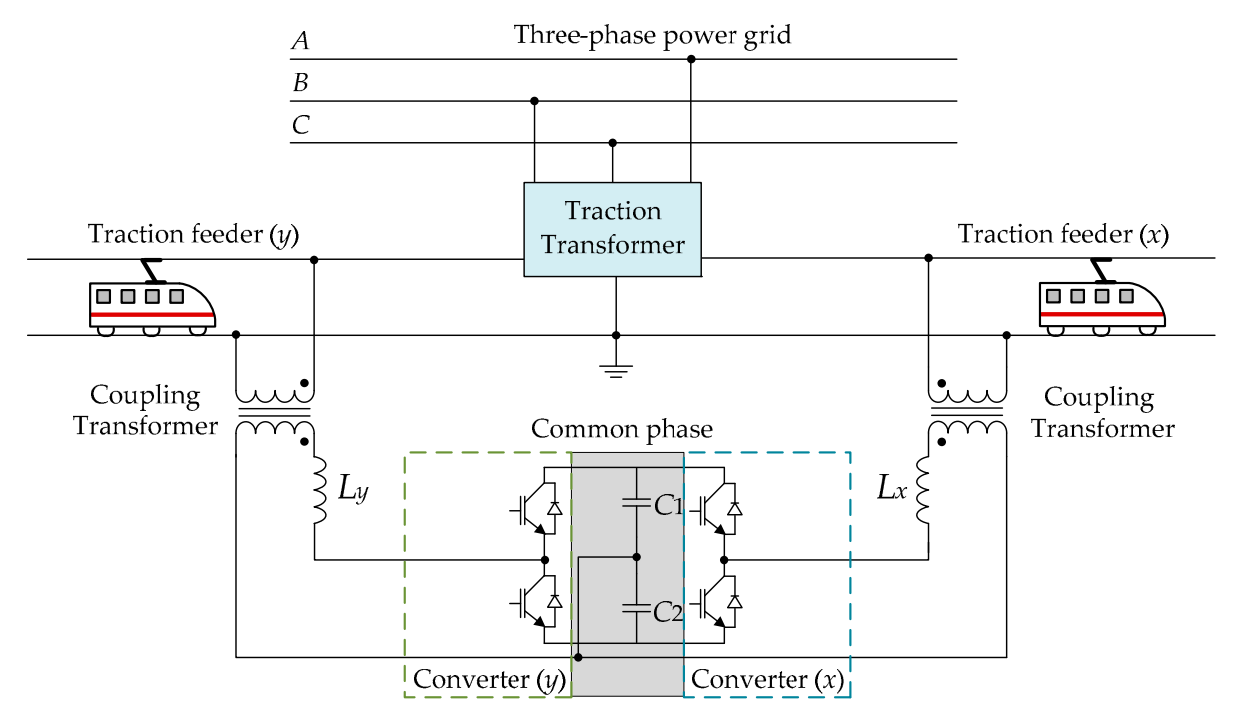

Figure 9. RPC based on a half-bridge two-level converter (HB-RPC) with coupling transformers (based on [27]).

Table 7. Components quantities of the HB-RPC.

\begin{tabular}{|c|c|c|c|}
\hline Number of IGBTs & Number of Capacitors & Number of Inductors & Isolation/Coupling Transformer \\
\hline 4 & 2 & 2 & 2 \\
\hline
\end{tabular}

\subsection{Modular RPC Units (MRPC)}

The modular rail power conditioner (MRPC) is mainly used to decrease the current stress of the semiconductor switches. The application of this topology is usual when a single RPC module cannot withstand the high values of the compensation currents. The step-down CT for each traction feeder is multiple secondary windings, as shown in Figure 10. Each RPC module contributes with a part of the total compensation currents. In addition, each control module should guarantee a constant DC-link voltage. The MRPC improves the power grid reliability as one or more of the RPC modules is out of service, the MRPC system can present power quality improvement, allowing full utilization of the installing capacity of the traction power transformer $[9,34]$. By considering $k$ as the number of FB-RPC units, Table 8 presents the components quantities of the MRPC.

Each RPC module can be treated as an independent FB-RPC unit. Consequently, the RPC module compensates a part of the reactive power and shifts a part of the active power difference between the feeder sections. The RPC module has its independent control in terms of producing the compensation current references and the DC-link voltage control. Therefore, it is not appropriate to use a common single DC-link for all the RPC modules. Otherwise, this will result in a bulky and expensive DC-link capacitor, besides the necessary coordinated control between the RPC modules in this case. In [37], a MRPC in a co-phase traction power supply system is presented, in which separated DC-links of the RPC power converters are used instead of a single DC-link between B2B converters, and, therefore, the two converters can operate independently with a relatively simple controlling method. However, due to the separated DC-links, the main drawback is that the active power cannot be exchanged between the RPC power converters, thus the compensation performance is just satisfactory for traction loads at nearly unitary power factor. 


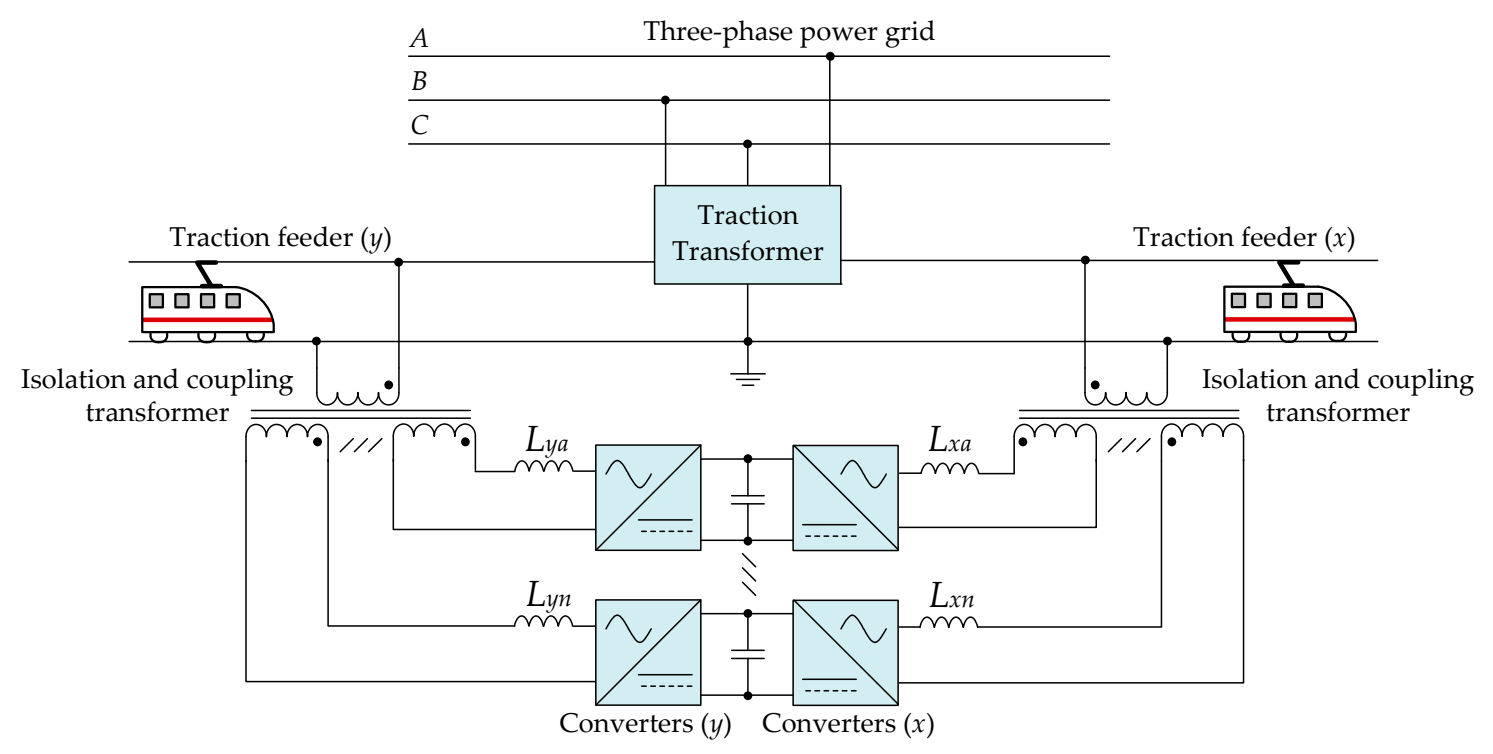

Figure 10. Modular RPC units (MRPC) with coupling transformers (based on [35]).

Table 8. Components quantities of the MRPC.

\begin{tabular}{|c|c|c|c|}
\hline Number of IGBTs & Number of Capacitors & Number of Inductors & Isolation/Coupling Transformer \\
\hline $8^{*} k$ & $k$ & $2^{*} k$ & 2 \\
\hline
\end{tabular}

Although the advantages of the MRPC topology, such as the scalability and better reliability, the main drawback of using this topology is its high implementation cost. The step-down CTs (one for each traction feeder) with multiple secondary windings are a bulky and costly solution. In addition, the FB-RPC modules can be processed independently due to the isolation of multiple secondary windings transformer. This means that the number of DC-link voltage controllers, current controllers, and pulse width modulation (PWM) generators are all proportional to the number of the FB-RPC modules [10].

\subsection{Hybrid Co-Phase RPC (co-HRPC)}

The aforementioned RPC topologies are connected to the traction power grid with an inductive coupling structure, bearing in mind that most of the traction loads are inductive in nature. This will increase the voltage drop across the coupling structure, leading to a higher RPC DC-link voltage. However, this voltage can be decreased by using a capacitive-inductive coupled structure such as a series LC branch [49]. The series LC passive filter is used to compensate harmonics, besides its main role in minimizing the RPC DC-link voltage. In this context, a developed system, called hybrid co-phase RPC (co-HRPC), eliminates the needs for a neutral section at the traction power grid when using a single-phase traction transformer, as shown in Figure 11. Table 9 presents the components quantities of the co-HRPC.

Despite the advantage of neutral section elimination in the co-phase connection (only the neutral sections in front of the traction substations), this is the worst operating scenario for the RPC converter. In a V/V power transformer, RPC shifts half of the active power difference from the highly to the lightly loaded traction feeder and provides all the reactive power. However, in a single-phase traction transformer, this active power magnitude is equal to half of the total load active power, which is the active power magnitude that the RPC should always shift when using a single-phase traction transformer. Hence, the RPC power ratings is higher. To overcome this problem, it is possible to include a capacitor in one coupling branch. In that case, RPC operational voltage is significantly reduced when compared to the conventional FB-RPC solution. Then, a lower DC-link voltage is required for the $\mathrm{B} 2 \mathrm{~B}$ converter, which reduces the power ratings of the power semiconductor switches 
as well. The capacitive coupling phase of the hybrid RPC is connected to the single-phase traction power grid. The other phase is connected to the three-phase power grid through a single-phase CT. It is worth mentioning that some studies recommend inserting a double asymmetric capacitive-inductive structure in the two coupling branches of the RPC for a better heavy-load compensation capacity and lower DC-link voltage [19].

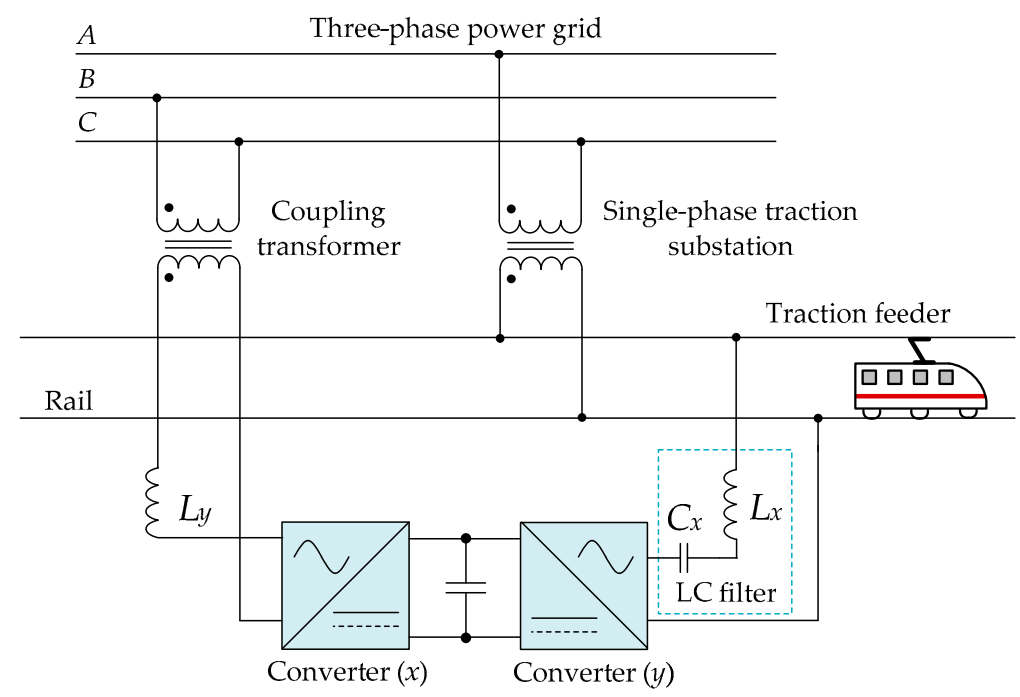

Figure 11. Hybrid co-phase RPC system (co-HRPC) (based on [20]).

Table 9. Components quantities of the co-HRPC.

\begin{tabular}{|c|c|c|c|}
\hline Number of IGBTs & Number of Capacitors & Number of Inductors & Isolation/Coupling Transformer \\
\hline 8 & 2 & 2 & 1 \\
\hline
\end{tabular}

In some applications, a partial compensation is implemented for a more economical solution, in which the compensation currents are expressed as a function of the power factor at the three-phase power grid [50]. The use of the partial compensation helps to reduce the co-HRPC power ratings. On the other hand, the co-HRPC can increase the loading capacity of the traction substation by transferring active power from the three-phase power grid to the single-phase traction substation. Moreover, when a full compensation is applied, all the reactive power is supplied by the co-phase hybrid RPC, maintaining a unitary power factor of the three-phase power grid [17].

Using double-side feeding co-phase substations, as shown in Figure 12, eliminates the neutral sections in front of the substations but the ones between the neighboring substations should remain for safety and security reasons. A double-side feeding system is applied when the load is always fed by two neighboring traction substations. When using double-side feeding V/V or Scott substations, the neutral sections in front of the substations, besides the ones between the neighboring substations, should remain. As a result, the total number of neutral sections could be reduced by half on the whole catenary line when using co-phase traction substations [51]. This allows the locomotives to reach a higher speed since they lose power and velocity when they are passing through the neutral sections [20]. The locomotives need fewer times and less time to pass the neutral sections. Co-HRPC system improves the traction performance by increasing the power capacity. Consequently, the co-phase system is more appropriate for supplying the high-speed railway than other traction schemes [14]. 


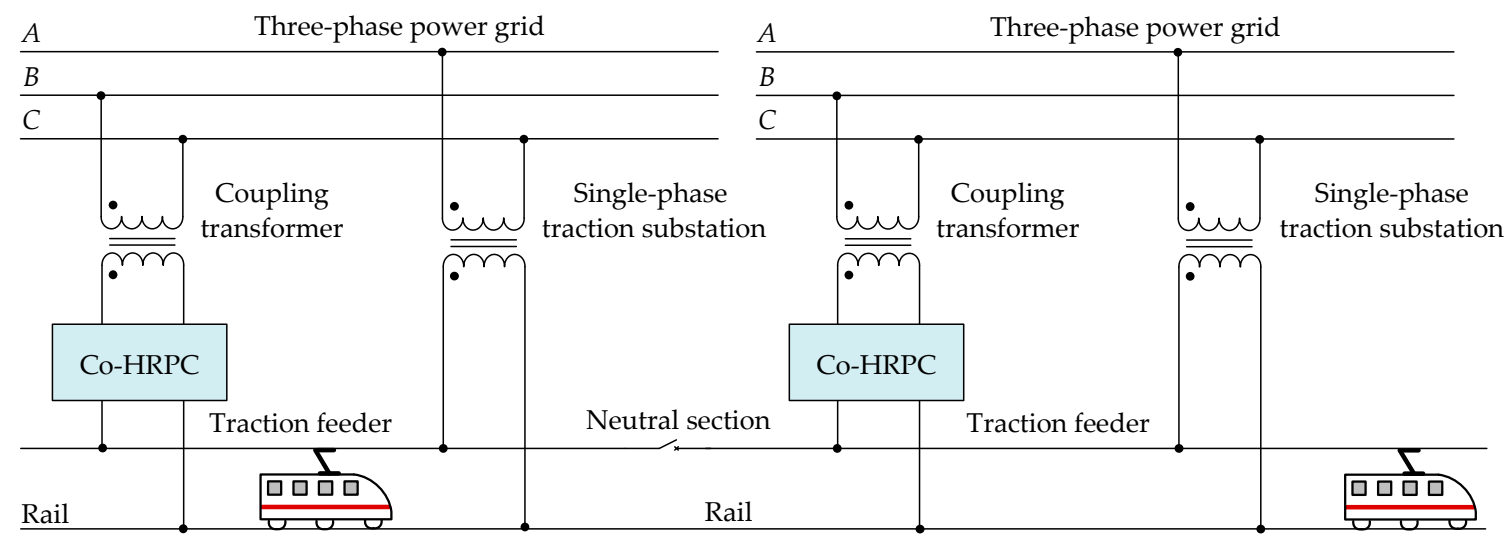

Figure 12. Double-side feeding co-HRPC substations (based on [20]).

\subsection{RPC Based on a Full-Bridge Indirect Modular Multilevel Converter (HB-MMC4 RPC)}

The conventional FB-RPC system based on two-level converters has some disadvantages in terms of the converter power ratings, and the high switching frequency applied on the switching devices. Over the last years, an important change has taken place toward SMs based topologies, in which cascade strings of converter SMs behave as controllable voltage sources [10]. To enhance the voltage and current ratings of the FB-RPC, several options in a modular manner were developed in the last decade in which the MMC was one of the applied choices. RPC based on MMC is an innovative solution since the total RPC power ratings will be divided among several cascade-connected SMs. Therefore, there is no need to use power electronic switches with high power ratings. In addition, MMC equivalent switching frequency is equal to the SM switching frequency multiplied by the number of SMs in each MMC arm [52]. Accordingly, MMC output waveforms will contain lower harmonic contents. MMC phase leg is divided into two equal arms (the number of SMs must be even) to be able to generate an equal number of positive and negative levels at the AC side [53]. The possibility to increase the total MMC power with ease, by inserting extra SMs, besides the high MMC reliability due to the MMC flexibility of redundancy, are extra advantages of the MMC [29]. Nowadays, the majority of the commercial MMC projects are based on the indirect AC/DC/AC MMC with half-bridge SMs [54]. This is due to the high efficiency of the half-bridge SM, besides its lower cost and simpler construction comparing to other types of SM [55].

The RPC based on a full-bridge indirect modular multilevel converter (HB-MMC4 RPC) is shown in Figure 13. Each half-bridge SM contains two switching devices and one capacitor that can be inserted or bypassed. The arm inductors are important to adjust the circulating current value between the MMC legs (the circulating currents are produced due to the inner DC-voltage differences between the MMC SMs [55]). In this topology, ITs with a turns ratio 1:1 are necessary to interface between the converter and the traction power grid. This is important to avoid short circuits between the MMC arms since two of the MMC legs are connected to the same ground [10]. HB-MMC4 RPC contains many power electronics equipment, the control strategy of this system is more complex than the aforementioned RPC topologies. This system is characterized by an inherent DC-link that is formed by the SM voltages of section $x$ and section $y$ converters. As a result, SM capacitors can effectively substitute the high-voltage DC-link capacitor [56]. Since $N$ is the MMC number of levels, $(N-1)$ is the number of SMs on one MMC arm. Table 10 presents the components quantities of the HB-MMC4 RPC. The discussion on analysis and control strategies for the HB-MMC4 RPC is presented in $[10,15,29]$. 


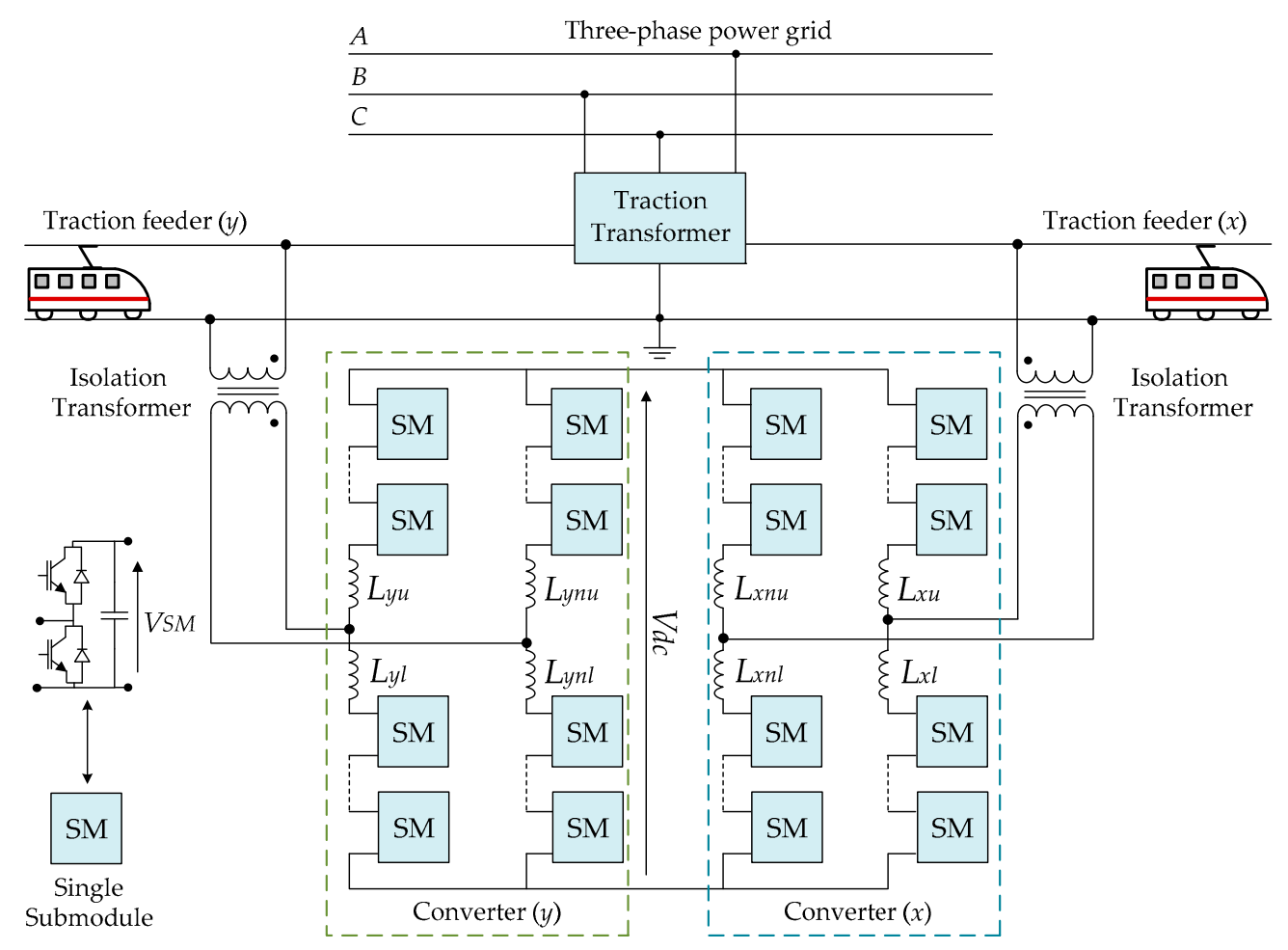

Figure 13. RPC based on a full-bridge indirect modular multilevel converter (HB-MMC4 RPC) with isolation transformers (based on [57]).

Table 10. Components quantities of the HB-MMC4 RPC.

\begin{tabular}{|c|c|c|c|}
\hline Number of IGBTs & Number of Capacitors & Number of Inductors & Isolation/Coupling Transformer \\
\hline $16(N-1)$ & $8(N-1)$ & 8 & 2 \\
\hline
\end{tabular}

\subsection{RPC Based on Two-Phase Three-Wire Indirect Modular Multilevel Converter (HB-MMC3 RPC)}

This topology is quite different from the HB-MMC4 RPC, and it can be considered as a three-phase MMC operating to compensate the NSC of currents and harmonics [10]. Since the RPC based on two-phase three-wire indirect modular multilevel converter (HB-MMC3 RPC) does not have the potential of an inherent DC-link between the converters, as is the case for the HB-MMC4 RPC, it is recommended to add a DC-link capacitor to insure a good performance as well as to reduce the size of the SM capacitors [58]. On the other hand, this solution does not require the use of step-down CTs or ITs to interface between the converter and the traction power grid, when the MMC level is quite enough to withstand the medium voltage value. The HB-MMC3 RPC topology is shown in Figure 14. Each half-bridge SM contains two switching devices and one capacitor, which could be inserted or bypassed. The leg inductors are considered as the converter inner filters, which are important to adjust the circulating current between the MMC arms.

This solution saves $25 \%$ of the hardware required in the HB-MMC4 RPC topology [58]. If $N$ as the MMC number of levels, then $(N-1)$ is the number of SMs in one MMC arm. Table 11 presents the components quantities of the HB-MMC3 RPC.

One of the HB-MMC3 RPC legs (the common phase) is connected to the grounded wire or the rail of the two single-phase traction feeders. Hence, a leg with $4(N-1)$ switching devices is saved when compared to the HB-MMC4 RPC. HB-MMC3 RPC has the same characteristics and it does the same as the HB-MMC4 RPC topology, while the rating of the switching devices in this solution does not increase $[10,58]$. In the HB-MMC3 RPC, the outer legs generate the compensation currents for phase $x$ and phase $y$, respectively. On the other hand, the inner leg generates the compensation current of the common ground phase. Therefore, all the IGBTs in the TW-RPC topology have homogeneous stress of 
currents and voltages [28]. The discussion on analysis and control strategies for the HB-MMC3 RPC is found in [10].

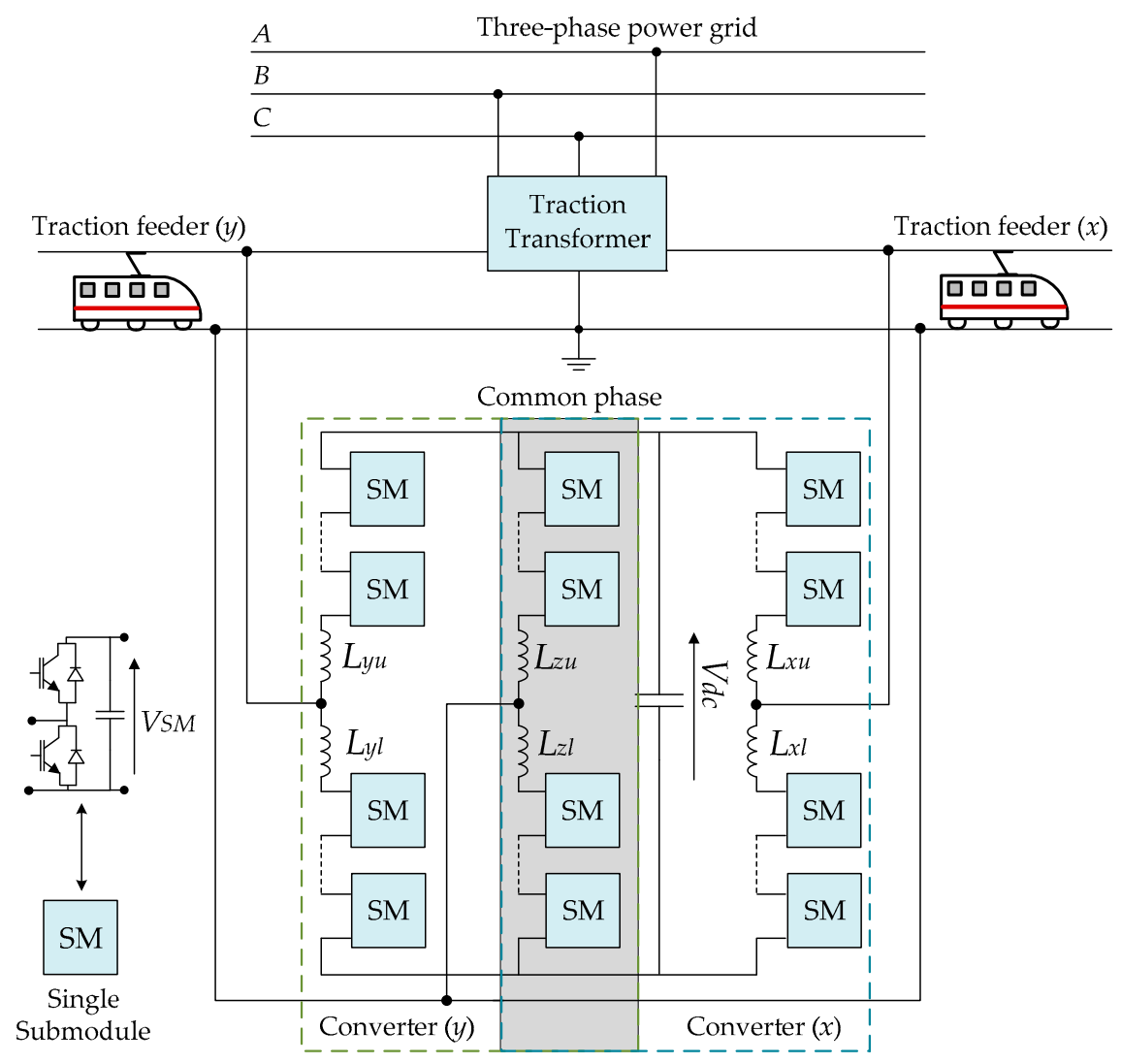

Figure 14. RPC based on two-phase three-wire indirect modular multilevel converter (HB-MMC3 RPC) (based on [58]).

Table 11. Components quantities of the HB-MMC3 RPC.

\begin{tabular}{|c|c|c|c|}
\hline Number of IGBTs & Number of Capacitors & Number of Inductors & Isolation/Coupling Transformer \\
\hline $12(N-1)$ & $6(N-1)+1$ & 6 & 0 \\
\hline
\end{tabular}

\subsection{Simplified RPC Based on a Half-Bridge Indirect Modular Multilevel Converter (HB-MMC2 RPC)}

The RPC based on a half-bridge indirect modular multilevel converter (HB-MMC2 RPC) has a simpler hardware structure when compared with the HB-MMC4 RPC and HB-MMC3 RPC [32]. The half-bridge MMC is a four-quadrant multilevel converter and its drawback is the fact that it requires the double of the phase voltage with respect to the output neutral. Therefore, two large bulk capacitors with a mid-neutral point are required, as shown in Figure 15. However, as shown in Figure 16, in the HB-MMC2 RPC, each DC-link capacitor is connected in series with a specific number of SMs, which is half the number of the SMs connected in the case of the HB-MMC4 RPC to generate a half-cycle of the sinusoidal waveform, which means, in the HB-MMC2 RPC, the power can be transferred to the output terminals during the on-time using half the number of the SMs required compared to the case of the HB-MMC4 RPC. This increases the efficiency (due to the lower power losses) of the HB-MMC2 RPC compared to the HB-MMC4 RPC. Since $N$ is the MMC number of levels, $(N-1)$ is the number of SMs in one MMC arm. Table 12 presents the components quantities of the HB-MMC2 RPC. 


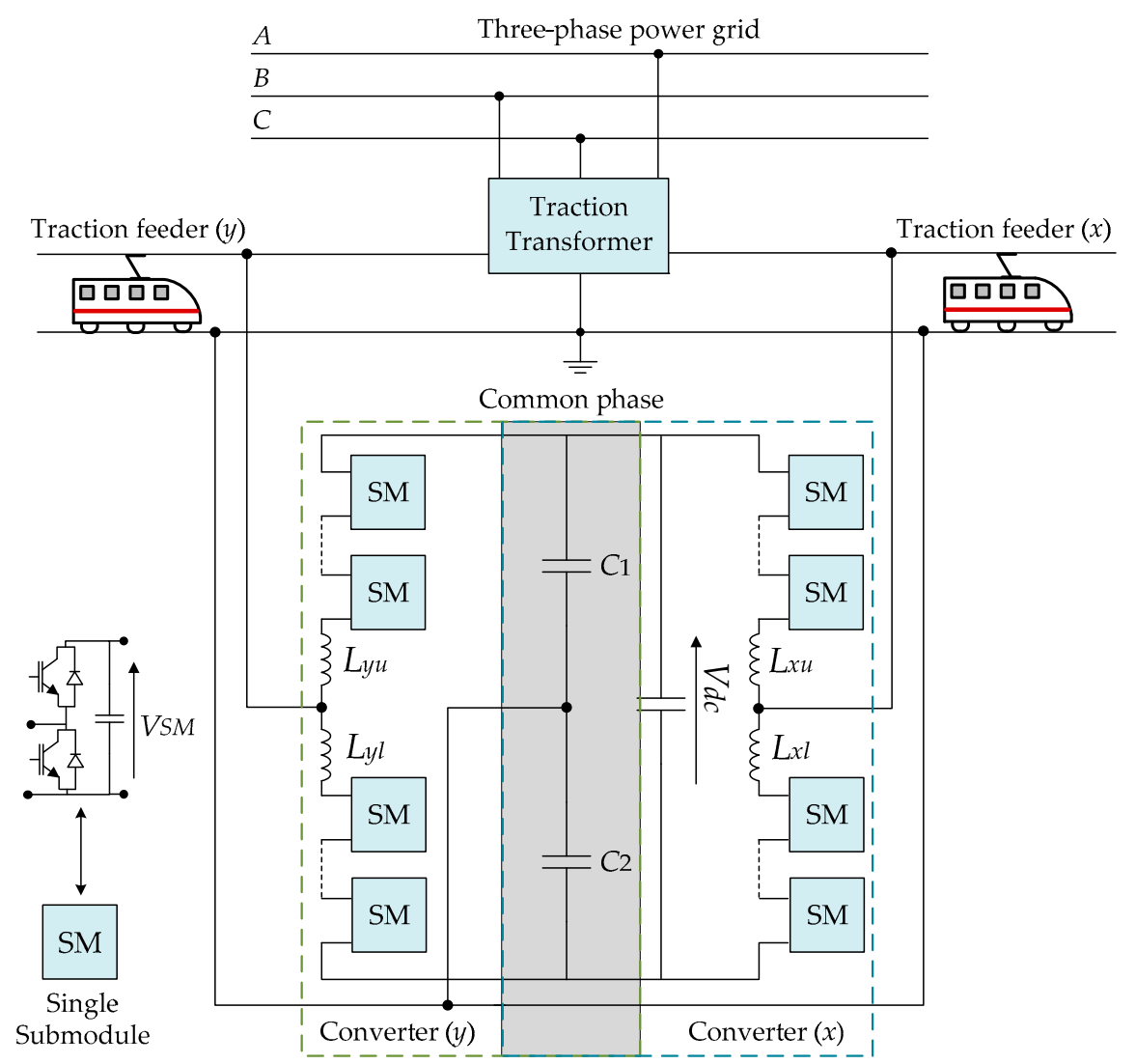

Figure 15. Simplified RPC based on a half bridge indirect modular multilevel converter (HB-MMC2 RPC) (based on $[31,58]$ ).

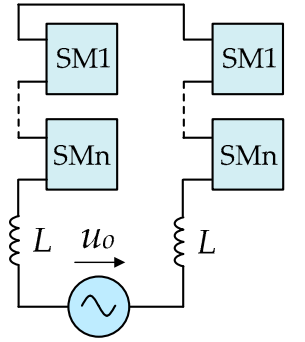

(a)

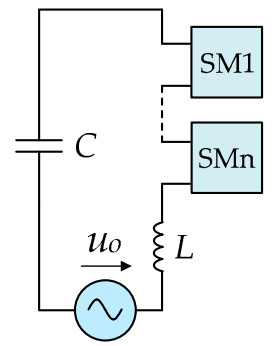

(b)

Figure 16. Number of SMs connected to the output terminals: (a) HB-MMC4; and (b) HB-MMC2.

Table 12. Components quantities of the HB-MMC2 RPC.

\begin{tabular}{|c|c|c|c|}
\hline Number of IGBTs & Number of Capacitors & Number of Inductors & Isolation/Coupling Transformer \\
\hline $8(N-1)$ & $4(N-1)+2$ & 4 & 0 \\
\hline
\end{tabular}

The main disadvantage of the HB-MMC2 RPC is that the main DC-link voltage ripple frequency is equal to the fundamental frequency of the traction power grid, which implies to use two large bulk capacitors with a mid-neutral point. This solution does not require the use of step-down CTs or ITs to interface between the converter and the traction power grid, when the MMC level is quite enough to withstand the medium voltage value. The switching stress for each switching device in the HB-MMC2 RPC should have double the value of the applied switching frequency in the HB-MMC3 RPC and HB-MMC4 RPC topologies. Otherwise, higher values of filter inductors is required for the HB-MMC2 RPC because of the high current ripple, as a result of the low equivalent switching frequency [8]. To some extent, although this topology has some drawbacks, it can offer a new attempt for power quality 
improvement in the railway system, which can expand the research ideas as well $[7,30]$. The analysis and control strategies for the HB-MMC2 RPC are presented in [30,53].

\subsection{RPC Based on Direct Modular Multilevel Converter (FB-MMC2 RPC)}

The HB-MMC4 RPC, HB-MMC3 RPC, and HB-MMC2 RPC are based on the indirect MMC, which is equipped with unidirectional half-bridge SM. However, the RPC based on direct modular multilevel converter (FB-MMC2 RPC) includes multiple cascade-connected bidirectional full-bridge SM, which can perform a direct $\mathrm{AC} / \mathrm{AC}$ conversion, as the full-bridge SM can operate in the four quadrants. As a result, the DC-link between the B2B converters can be avoided in this topology, as shown in Figure 17 [33]. Each full-bridge SM contains four switching devices and one capacitor, which can be inserted or bypassed. When using the FB-MMC2 RPC in a co-phase supply mode with only one traction feeder, it can be directly connected to the single-phase traction power grid, without step-down CTs $[9,32]$. However, in the conventional railway system with two traction feeders, ITs are important to avoid short circuits of some SMs.

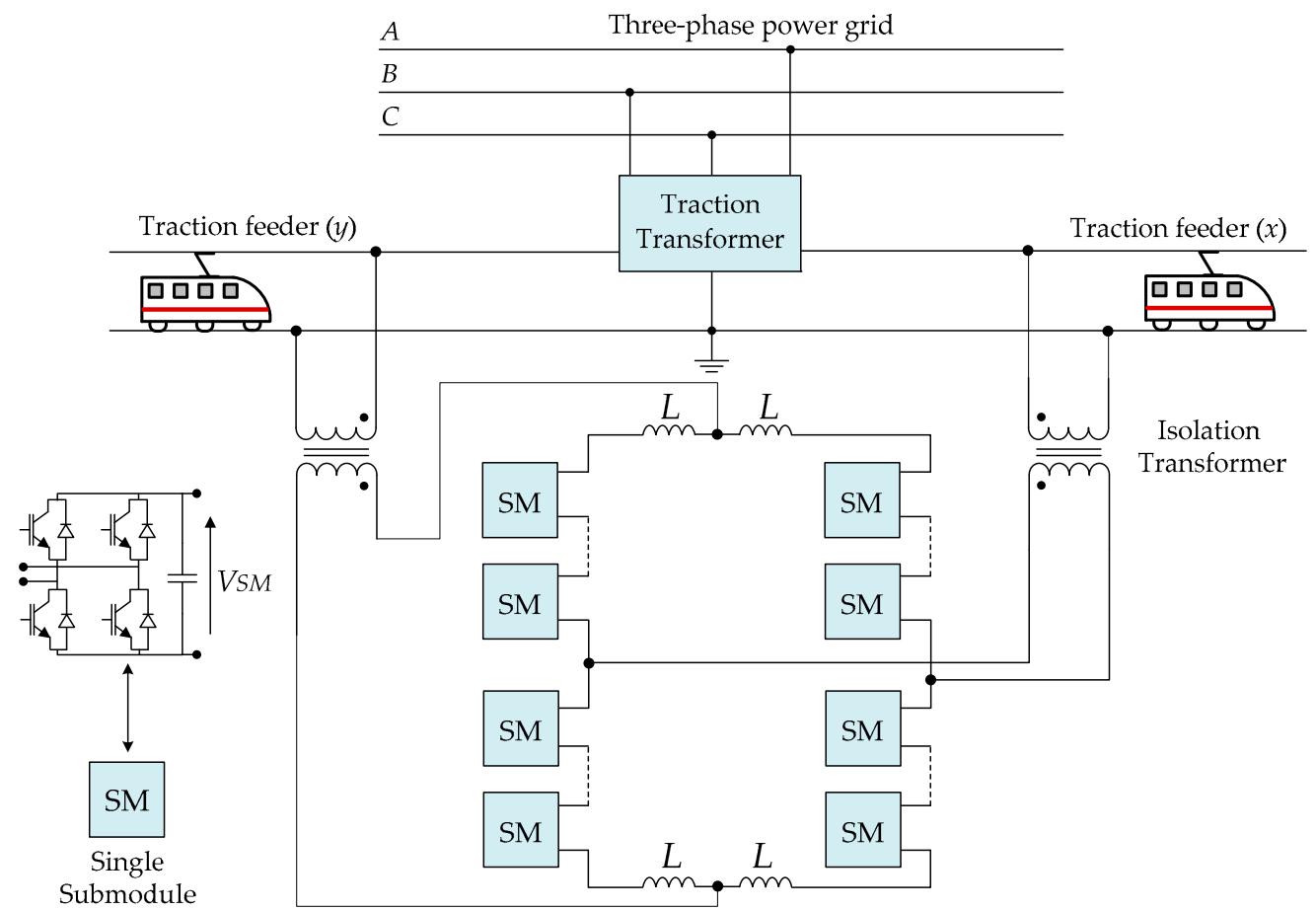

Figure 17. RPC based on direct modular multilevel converter (FB-MMC2 RPC) with isolation transformers (based on [33]).

Due to the direct AC/AC power conversion of the FB-MMC2 RPC and the full-bridge SM structure, the control of this system is more complex than the RPC based on the indirect MMC topologies [33]. If $N$ is the MMC number of levels, then $(N-1)$ is the number of SMs in one MMC arm. Table 13 presents the components quantities of the FB-MMC2 RPC. According to the analysis of the FB-MMC2 RPC equivalent electrical model presented in [33], this solution can be used for different traction power grids, but it is more appropriate with the Scott power transformer. The discussion on analysis and control strategies for the FB-MMC2 RPC is found in $[9,32]$.

Table 13. Components quantities of the FB-MMC2 RPC.

\begin{tabular}{|c|c|c|c|}
\hline Number of IGBTs & Number of Capacitors & Number of Inductors & Isolation/Coupling Transformer \\
\hline $16(N-1)$ & $4(N-1)$ & 4 & 2 \\
\hline
\end{tabular}




\section{Comprehensive Comparison between the RPC Topologies in V/V and Scott Power Transformers}

The RPC characteristics are not only dependent on the type of the RPC topology, but also the type of the traction power system. In this context, among the presented RPC topologies based on different converters and different types of traction power system, a major question must be discussed about the characteristics of the RPC topologies, including the advantages, disadvantages, and differences among these topologies in V/V and Scott power transformers. In other words, what are the satisfactory conditions for each RPC topology to operate and when can be effectively utilized either in the V/V or in the Scott traction power system? In this framework, RPC analysis in V/V and Scott power transformers is provided, showing the main differences that must be considered in the design process of the RPC system.

\subsection{RPC Analysis in V/V and Scott Power Transformer}

Figure 18 shows the RPC system in V/V and Scott power transformer, besides the associated phasor diagrams. Normally, V/V and Scott power transformers are used to perform the three-phase to two-phase conversion. In this regard, $\mathrm{V} / \mathrm{V}$ power transformers are widely used in the high-speed railway due to their simple structure, low cost, and the high overloading capability [6]. It is important to declare that, when using V/V power transformer, the NSC of currents injected into the three-phase power grid is half of the fundamental positive sequence components when both traction feeders are equally loaded [6]. In these conditions, there is no active power shifting between the feeder sections, but reactive power for NSC and harmonics compensation must be applied by the RPC to obtain balanced three-phase currents and unitary power factor. This is the best operation scenario for the RPC system with V/V power transformer.
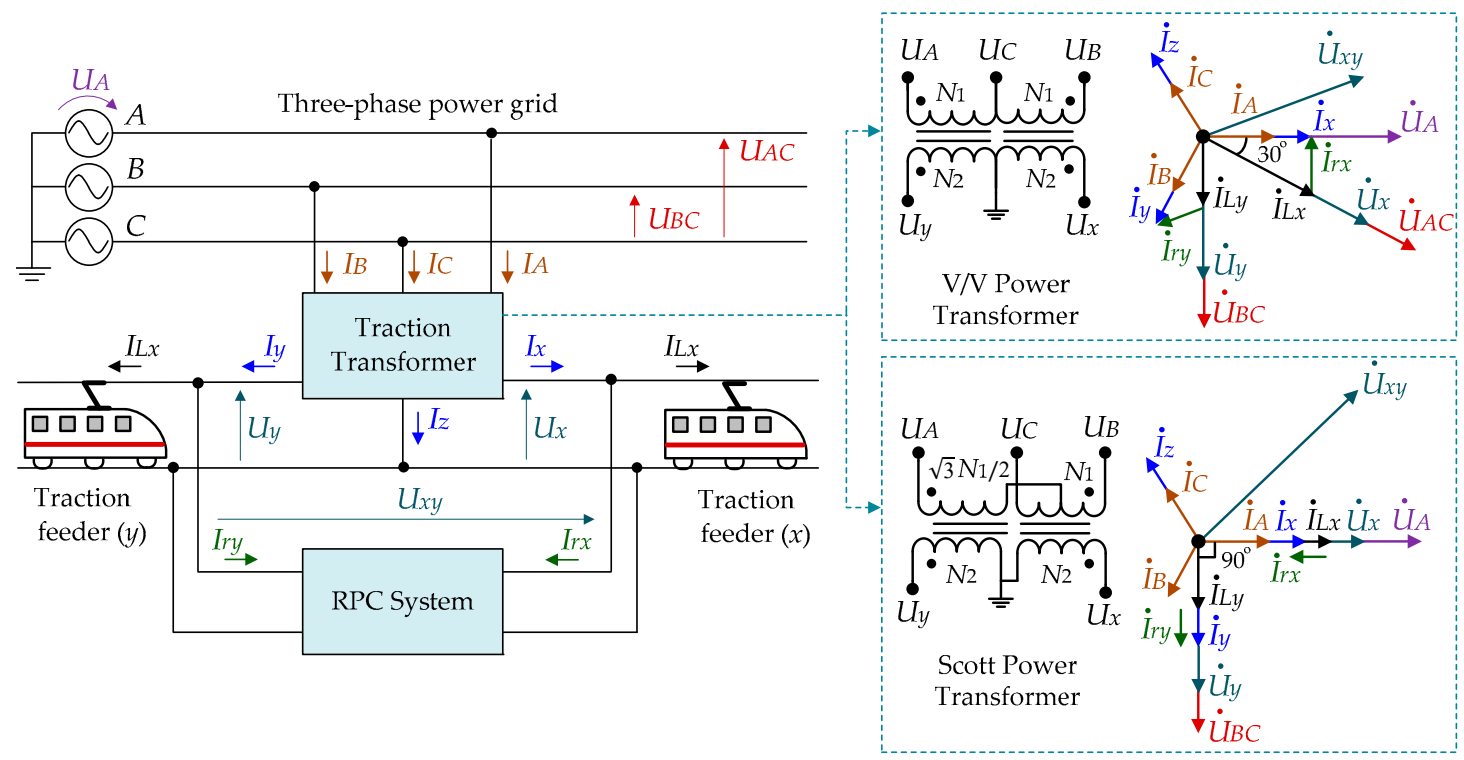

Figure 18. RPC system and phasor diagrams in V/V and Scott power transformer (based on [10,48]).

Despite the complex structure of the Scott power transformers when compared to the $\mathrm{V} / \mathrm{V}$ power transformers, Scott power transformers have several advantages regarding the power quality improvement capability [59]. For instance, when the traction feeders are equally loaded, no active power shifting and no reactive power for NSC compensation are applied by the RPC. However, when the traction feeders are unequally loaded, the Scott power transformer helps to reduce the reactive power produced by the RPC for NSC compensation. Nevertheless, in this case, an additional amount of reactive power for harmonics compensation can be produced by the RPC system as well. As a result, reactive power compensation is not a vital issue in the RPC with Scott power transformer, but it is fundamental in the RPC with the V/V power transformer. Accordingly, due to the difference in reactive 
power compensation, the compensation capacity of the RPC with the V/V power transformer is a little higher than the RPC with the Scott power transformer [10]. The phasor diagrams in Figure 18 show $60^{\circ}$ out-of-phase and $90^{\circ}$ out-of-phase between the traction feeder voltages, $U_{x}$ and $U_{y}$, in the V/V and Scott power transformers, respectively. Consequently, in the V/V power transformer, the line-to-line or the voltage between traction feeders, $U_{x y}$, has a root mean square (RMS) voltage equals to the one of the traction feeder voltages. However, in the Scott power transformer, the voltage, $U_{x y}$, has a higher RMS value than the traction feeder voltages, which results in a higher DC-link voltage of the RPC. This is only correct in the RPC topologies that designed with respect to the line-to-line voltage (TW-RPC, HB-RPC, HB-MMC3, and HB-MMC2).

Figure 19a presents the RPC output voltages in the V/V power transformer, and Figure $19 \mathrm{~b}$ in the Scott power transformer. In the V/V power transformer, phase $x$ output voltage of the RPC, $U_{x o(V / V)}$, is higher than the phase $y$ output voltage, $U_{y o(V / V)}$. Therefore, phase $x$ output voltage is the value that should be considered in the design process of the RPC in V/V power transformer. Then, the RPC phases and the associated power equipment, in this case, suffer from asymmetrical loading conditions. On the contrary, in Scott power transformer, phase $x$ output voltage of the RPC, $U_{x o(V / V)}$, is similar to the phase $y$ output voltage, $U_{y o(V / V)}$. Then, the RPC phases and the associated power equipment, in this case, have symmetrical loading conditions. Apparently, as shown in Figure 19, the DC-link voltage of the RPC should be higher when using the V/V power transformer. This is only correct in the $\mathrm{RPC}$ topologies that have $\mathrm{B} 2 \mathrm{~B}$ converters and designed with respect to the phase-to-neutral voltages (e.g., FB-RPC, MRPC, Co-HRPC, and HB-MMC4 RPC).

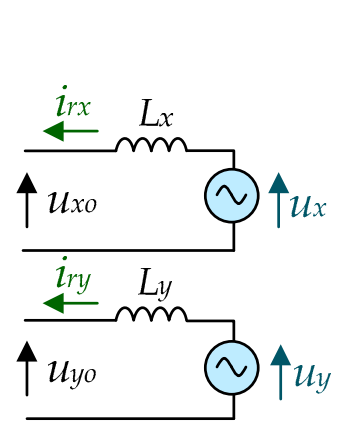

(a)

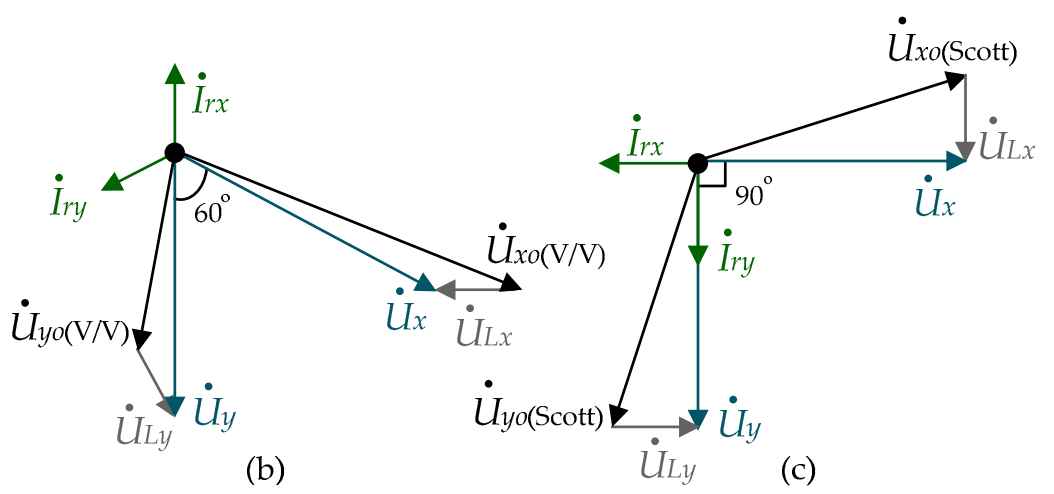

Figure 19. RPC output equivalent circuit and phasors of output voltages: (a) output equivalent circuit of the RPC; (b) phasors of the RPC output voltages in V/V power transformer; and (c) phasors of the RPC output voltages in Scott power transformer (based on [10]).

\subsection{Case Study: Simulation of the FB-RPC Topology in V/V and Scott Power Transformer}

A comparative study between the FB-RPC in V/V and Scott power transformers has been established by using the PSIM 9.1 software. The simulation model is based on Figure 18, but after substituting the RPC system block with the FB-RPC system presented in Figure 7. The simulation parameters are presented in Table 14 after considering a unitary load power factor for both traction feeders. Figure 20a shows the performance of each traction power transformer (V/V and Scott power transformer) when both traction feeders $x$ and $y$ are equally loaded (each traction feeder is loaded with 4.8 MW at three-phase power grid line-to-line voltage $220 \mathrm{kV}$ ). Along the simulation period, the FB-RPC is turned off and there are no compensation currents injected into the three-phase power grid. Figure 20a (A) presents the three-phase currents at the primary winding of the V/V power transformer and without compensation. The positive sequence component (PSC) and the NSC of the three-phase currents are calculated at the fundamental frequency of $50 \mathrm{~Hz}$, as shown in Figure 20a (B). In this case, the NSC of currents is almost $50 \%$ of the PSC at the fundamental frequency of $50 \mathrm{~Hz}$. On the other hand, the simulation results when using the Scott power transformer show a very good ability to present balanced three-phase currents without any compensation, as shown in Figure 20a (C). The NSC 
of currents, in this case, is near zero, as shown in Figure 20a (D), and the three-phase currents only contain harmonic contents.

Table 14. Parameters of the FB-RPC simulation model.

\begin{tabular}{|l|c|c|}
\hline Description & Symbols & Value \\
\hline Three-phase power grid line-to-line voltage & $U_{A B}, U_{B C}, U_{C A}$ & $220 \mathrm{kV}$ \\
\hline Catenary voltage & $U_{x,}, U_{y}$ & $27.5 \mathrm{kV}$ \\
\hline RPC filter inductance & $L_{x}, L_{y}$ & $2.2 \mathrm{mH}$ \\
\hline Capacitance of the DC-link capacitor & $C_{d c}$ & $80 \mathrm{mF}$ \\
\hline Turns ratio of the V/V power transformer & $K_{V}$ & $220 / 27.5$ \\
\hline Turns ratio of the step-down coupling transformer & $K_{D}$ & $27.5 / 1$ \\
\hline
\end{tabular}

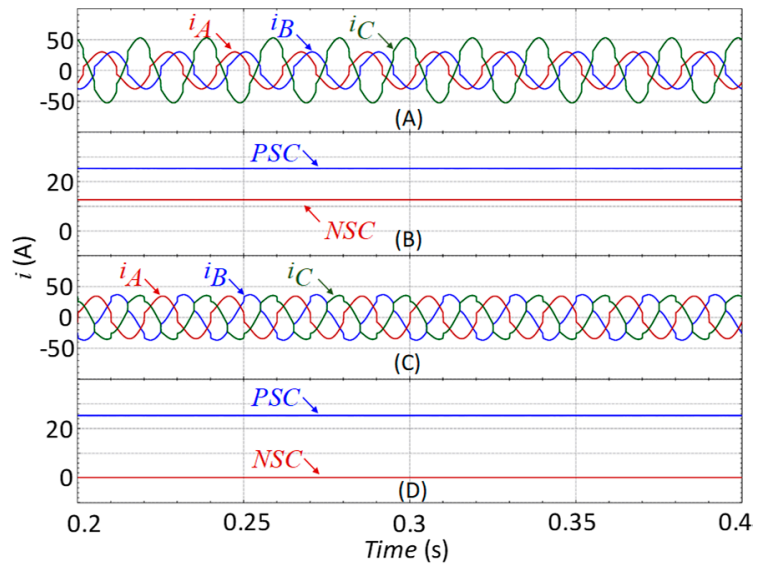

(a)

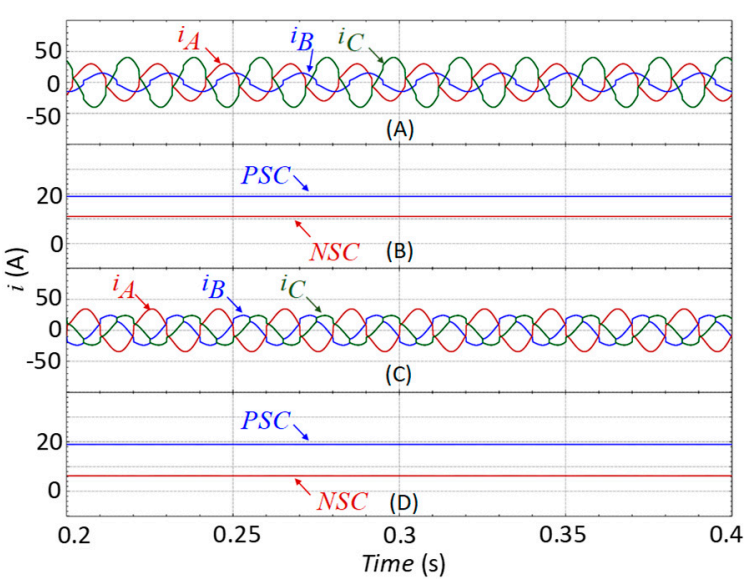

(b)

Figure 20. Three-phase power grid currents, PSC, and NSC of currents in V/V and Scott traction power systems: when the feeder sections are equally loaded (a); and when the feeder section $x$ has double the load of the feeder section $y(\mathbf{b})((\mathrm{A}, \mathrm{B})$ when using the $\mathrm{V} / \mathrm{V}$ traction power system; and $(\mathrm{C}, \mathrm{D})$ when using the Scott traction power system).

Scott power transformer shows a better power quality improvement capability than the V/V power transformer, even when both traction feeders are unequally loaded (traction feeder $x$ is loaded with 4.8 MW and traction feeder $y$ is loaded with 2.4 MW), as shown in Figure 20b [59]. In this case, the NSC of currents at the fundamental frequency of $50 \mathrm{~Hz}$ when using the Scott power transformer was lower than the NSC when using the V/V power transformer. The NSC of currents has a value of more than $50 \%$ of the PSC when using the V/V power transformer, while the NSC of currents has a value lower than $40 \%$ of the PSC when using the Scott power transformer.

Figure 21a,b shows the three-phase grid currents, PSC, and NSC of currents before and after compensation when using the FB-RPC with the V/V and Scott power transformers, respectively. The FB-RPC is turned on after $0.1 \mathrm{~s}$ and when both traction feeders are unequally loaded (traction feeder $x$ : 4.8 MW; traction feeder $y$ : 2.4 MW). Before the indicated time (0.1 s), the three-phase currents are imbalanced and the NSC of currents has a higher value when using the V/V power transformer. After $0.1 \mathrm{~s}$, the RPC is turned on to compensate both of harmonics and NSC of currents. Consequently, as shown in Figure 21a,b (C), the NSC of currents at the fundamental frequency $50 \mathrm{~Hz}$ is reduced to be almost zero. Figure 21a,b (B) shows the secondary windings currents of the V/V and Scott power transformers, respectively. The secondary windings currents of the Scott power transformer are imbalanced since the primary and the secondary windings end points of the Scott power transformer are different. This imbalance does not appear when using the V/V power transformer, as shown in Figure 21a (B), since it has common windings end points on the primary and the secondary sides. 


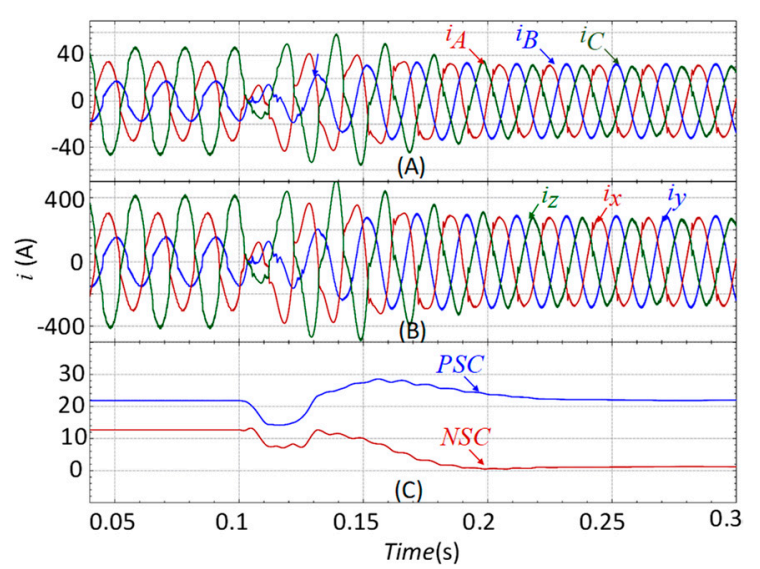

(a)

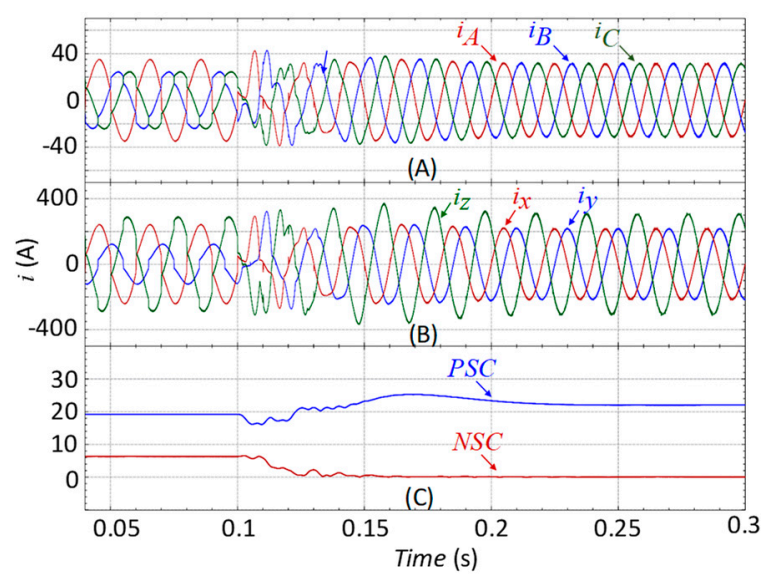

(b)

Figure 21. Three-phase power grid currents, PSC, and NSC of currents in V/V traction power system (a) and Scott traction power system (b) when the feeder section $x$ has double the load of the feeder section y: (A) three-phase currents after compensation at the primary windings of the power transformer; (B) three-phase currents after compensation at the secondary windings of the power transformer; and (C) PSC and NSC of currents before and after compensation.

Figure 22a,b shows the FB-RPC simulation results after compensation when using the V/V power transformer and the Scott power transformer, respectively. Figure 22a,b (A) shows the traction feeder currents which considered as harmonics sources. These currents have a constant RMS value during the simulation. Figure 22a,b (B) presents the compensation currents synthesized by the FB-RPC converter when using the V/V and Scott power transformers, respectively. Apparently, the FB-RPC in the V/V power transformer has a higher demand for power compensation. On the other hand, as mentioned above, using the Scott power transformer in traction applications will lead to a decrease of the required DC-link voltage $\left(V_{d c} \geq \sqrt{2} U_{x o(S c o t t)}\right)$. Consequently, as shown in Figure $22 \mathrm{~b}(\mathrm{C})$, the initial value of the DC-link voltage is $1.5 \mathrm{kV}$ before turning on the FB-RPC. In the steady-state and after synthesizing the compensation currents, the DC-link voltage reached a value near of $1.8 \mathrm{kV}$. The DC-link voltage when using $\mathrm{V} / \mathrm{V}$ power transformer and at the loading conditions is around $2 \mathrm{kV}\left(V_{d c} \geq \sqrt{2} U_{x o}(\mathrm{~V} / \mathrm{V})\right)$, as shown in Figure 22a (C). There is a proportional-integral controller to regulate the DC-link voltage in a closed-loop. Therefore, in the steady-state operation, the DC-link voltage will be kept constant, according to its reference value.

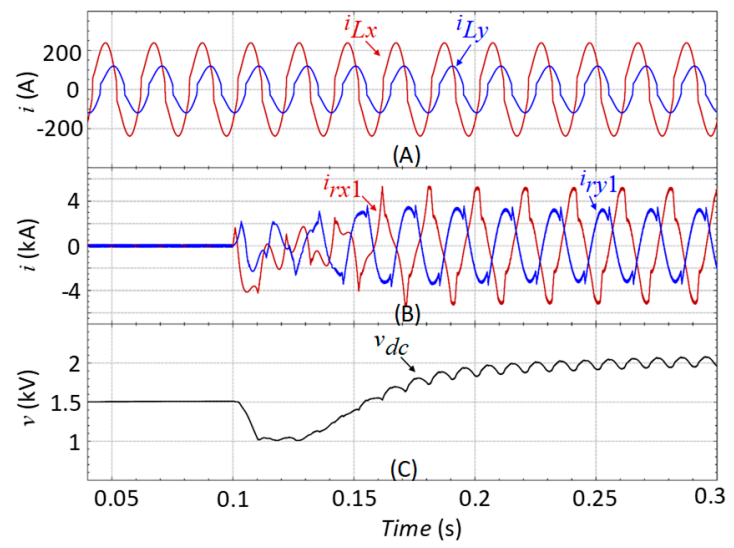

(a)

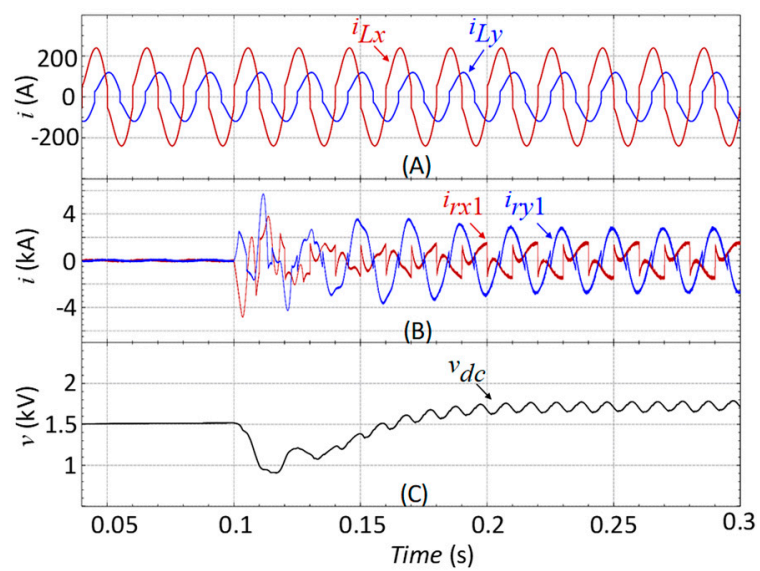

(b)

Figure 22. Simulation results of the FB-RPC in V/V traction power system (a) and in Scott traction power system (b) when the feeder section $x$ has double the load of the feeder section $y$ : (A) currents of the feeder sections; (B) compensation currents synthesized by the FB-RPC; and (C) DC-link voltage of the FB-RPC. 


\subsection{Comparative Study between the RPC Topologies in V/V and Scott Power Transformer}

For the objective of comparison, V/V and Scott power transformers are both used for all the aforementioned RPCs. In addition, the multilevel RPC topologies are considered with a similar MMC voltage level of $N$. In this context, Table 15 presents the IGBT characteristics of the RPC topologies. Normally, the multilevel RPC topologies, such as HB-MMC4 RPC and FB-MMC2 RPC, require the highest number of the switching devices, but the RPCs based on half-bridge topologies, such as HB-RPC and HB-MMC2 RPC, need a lower number of the IGBT switching devices. Other important factors in the IGBT selection are the applied current and voltage stress. Hereafter, and by considering that each of the RPC topologies must synthesize similar compensation current waveforms, the MRPC topology has the lowest IGBT current stress since each RPC module synthesizes only a portion of the total compensation current. However, the IGBT current stress in the FB-MMC2 RPC topology is quite different and considered the highest, especially in the $\mathrm{V} / \mathrm{V}$ power system. In this case, the reactive power compensation is a vital factor and obligates to inject circulating voltages and currents. As a result, the RMS values of the MMC arm currents will be higher than these when using the FB-MMC2 RPC topology with the Scott power transformer, where reactive power compensation is not a vital factor and it is not important to inject circulating currents to maintain balanced SM voltages [10].

Table 15. IGBT characteristics of the RPC topologies (based on $[6-8,10,33]$ ).

\begin{tabular}{|l|c|c|c|c|}
\hline & Number of IGBTs & IGBT Current Stress & IGBT Voltage Stress & IGBT Switching Frequency \\
\hline FB-RPC & 8 & 1 p.u. & $0.5 V_{d c}$ & $f_{i s w}$ \\
\hline TW-RPC & 6 & 1 p.u. & $0.5 V_{d c}$ & $f_{i s w}$ \\
\hline HB-RPC & 4 & 1 p.u. & $V_{d c}$ & $2 f_{i s w}$ \\
\hline MRPC & $8 k$ & $1 / k$ p.u. & $0.5 V_{d c k}$ & $f_{i s w}$ \\
\hline Co-HRPC & 8 & $\approx 1$ p.u. & $<0.5 V_{d c}$ & $f_{i s w}$ \\
\hline HB-MMC4 RPC & $16(N-1)$ & 1 p.u. & $V_{S M}=V_{d c} /(N-1)$ & $f_{i s w} /(N-1)$ \\
\hline HB-MMC3 RPC & $12(N-1)$ & 1 p.u. & $V_{S M}=V_{d c} /(N-1)$ & $f_{i s w} /(N-1)$ \\
\hline HB-MMC2 RPC & $8(N-1)$ & 1 p.u. & $V_{S M}=V_{d c} /(N-1)$ & $2 f_{i s w} /(N-1)$ \\
\hline FB-MMC2 RPC & $16(N-1)$ & $>1$ p.u. ${ }^{*}$ or $\approx 1$ p.u. ${ }^{* *}$ & $0.5 V_{S M}$ & $f_{i s w} /(N-1)$ \\
\hline
\end{tabular}

${ }^{*}$ In V/V power transformer, ${ }^{* *}$ In Scott power transformer.

Regarding the multilevel RPC topologies, and by considering an identical MMC voltage level, $N$, and equal SM DC-link voltages, $V_{S M}$, the IGBT voltage stress is the lowest in the FB-MMC2 RPC, due to the used full-bridge SM topology [33]. In this case, the voltage stress across one IGBT is half of the SM voltage, $V_{S M}$. On the other hand, the IGBT voltage stress in the HB-MMC4, HB-MMC3, and the HB-MMC2 are equal to the SM voltage due to the half-bridge SM topology. In the FB-RPC and the TW-RPC, the IGBT voltage stress is equal to half of the RPC DC-link voltage, $V_{d c}$, but it is double this value in the HB-RPC due to the half-bridge topology [6-8]. In the hybrid RPC topology with a single or double LC passive filter-branch, the IGBT voltage stress is lower than half of the RPC DC-link voltage due to the capacitive coupling structure [19].

In fact, the IGBT switching frequency is an important parameter and has a direct influence on the RPC power losses. By considering the same carrier frequency and equal passive inductors for all of the RPC topologies, the IGBT switching stress in the HB-RPC must be twice the value in the FB-RPC and TW-RPC to have synthesized compensation currents with similar current ripples [8]. As a result, the switching stress in the half-bridge RPC topologies, such as HB-RPC and HB-MMC2, RPC is double and the associated switching losses are double as well. In the multilevel RPC topologies, the switching frequency of one IGBT is significantly lower since the switching stress can be divided among several cascade-connected SMs (N-1) in one MMC arm.

Table 16 presents a quantitative comparison of the RPC topologies after considering the same MMC voltage level, $N$, for the multilevel RPC topologies. Apparently, HB-MMC4 RPC requires the highest number of capacitors since this topology is based on B2B MMCs. The number of capacitors in the HB-RPC has double the value in the FB-RPC and the TW-RPC. However, in the MRPC, the number of capacitors 
is equal to the number of RPC modules. On the other hand, in the co-HRPC, the number of capacitors depends on whether the co-HRPC has a single or double LC series filter in the two coupling branches of the RPC, where, in the first case, the RPC only contains two capacitors and, in the second case (double capacitive-inductive structure), the RPC contains three capacitors. Moreover, the filter inductors are indispensable to smooth the synthesized compensation currents produced by the RPC. In this context, as presented in Table 16, the number of the filter inductors in most of the RPC topologies is constant. The HB-MMC4 RPC topology needs the highest number of the filter inductors. However, in the MRPC topology, the total quantity of the filter inductors is related to the number of the RPC modules, $k$.

Table 16. Quantitative comparison of the RPC topologies (based on $[6-8,10,33]$ ).

\begin{tabular}{|l|c|c|c|c|}
\hline & $\begin{array}{c}\text { Number of } \\
\text { Capacitors }\end{array}$ & $\begin{array}{c}\text { Number of } \\
\text { Inductors }\end{array}$ & $\begin{array}{c}\text { Coupling } \\
\text { Transformers (CTs) }\end{array}$ & $\begin{array}{c}\text { Isolation } \\
\text { Transformers (ITs) }\end{array}$ \\
\hline FB-RPC & 1 & 2 & Yes $(2)$ & Inherent \\
\hline TW-RPC & 1 & 2 & Yes $(2)$ & Inherent \\
\hline HB-RPC & 2 & 2 & Yes (2) & Inherent \\
\hline MRPC & $k$ & $2 k$ & Yes $(2 k)$ & Inherent \\
\hline Co-HRPC & 2 or 3 & 3 & Yes $(1)$ & Inherent \\
\hline HB-MMC4 RPC & $8(N-1)$ & 8 & No & Nos $(2)$ \\
\hline HB-MMC3 RPC & $6(N-1)+1$ & 6 & No & No \\
\hline HB-MMC2 RPC & $4(N-1)+2$ & 4 & No & Yes $(2)$ \\
\hline FB-MMC2 RPC & $4(N-1)$ & 4 & No & \\
\hline
\end{tabular}

CTs are important to step-down the traction power grid voltage and to achieve the necessary galvanic isolation between the RPC converter and the traction power grid. In this context, the CTs are dispensable in the multilevel RPC topologies (HB-MMC4, HB-MMC3, HB-MMC2, and FB-MMC2) since an MMC with a high level allows a direct interface with the traction power grid. Nevertheless, the HB-MMC4 RPC and FB-MMC2 RPC topologies require two ITs (with turns ratio of 1/1) to prevent short circuits between the MMC SMs [10]. However, when using the HB-MMC4 RPC and FB-MMC2 RPC topologies in the co-phase traction grid, the ITs are dispensable [33]. It is worth mentioning that the galvanic isolation is inherent in the RPC topologies that use the CTs.

Table 17 presents different characteristics of the RPC topologies in the V/V and Scott power transformers. The most important parameter that makes a difference is the RPC DC-link voltage, which is normally higher in the V/V power transformer than the case when using the Scott power transformer $\left(U_{x o(V / V)}>U_{x o(S c o t t)}\right)$, as shown in Figure 19. However, this is only true in the FB-RPC, MRPC, co-HRPC, and HB-MMC4 RPC, where the common denominator of these topologies is the four wires $\mathrm{B} 2 \mathrm{~B}$ converter. On the other hand, in the RPC topologies where a common phase exists, such as TW-RPC, HB-RPC, HB-MMC3 RPC, and HB-MMC2 RPC, the DC-link voltage is higher in the Scott power transformer than the case of the V/V power transformer. As a result, the FB-RPC, MRPC, co-HRPC, and HB-MMC4 RPC, are considered as power compensators for wider applications and they are quite appropriate for the applications of power quality improvement in the $\mathrm{V} / \mathrm{V}$ or the Scott power transformers. On the contrary, the RPC topologies with a common phase, such as TW-RPC, HB-RPC, HB-MMC3 RPC, and HB-MMC2 RPC, are considered as power compensators for limited applications. The TW-RPC, HB-RPC, and HB-MMC3 RPC are only appropriate for the power quality improvement in the V/V traction power system, while the FB-MMC2 RPC is the adequate choice for the Scott traction power system, due to the not needed circulating current between the MMC arms. Moreover, using the FB-MMC2 RPC in a co-phase Scott traction power system is the optimal scenario to save the additional costs resulting from the required ITs in the conventional Scott traction power system [33]. 
Table 17. Characteristics of the RPC topologies in V/V and Scott transformer (based on $[6-8,10,33]$ ).

\begin{tabular}{|c|c|c|c|c|c|}
\hline & RPC DC-link Voltage & $\begin{array}{c}\text { Control } \\
\text { Complexity }\end{array}$ & Reliability/Perfo & $\begin{array}{c}\text { Estimated } \\
\text { Costs }\end{array}$ & $\begin{array}{c}\text { Required } \\
\text { Volume }\end{array}$ \\
\hline \multicolumn{6}{|c|}{$\mathrm{V} / \mathrm{V}$ power transformer } \\
\hline FB-RPC & $V_{d c} \geq \sqrt{2} U_{x o(\mathrm{~V} / \mathrm{V})}$ & +++ & +++ & +++ & +++ \\
\hline TW-RPC & $V_{d c} \geq \sqrt{2} U_{x o(\mathrm{~V} / \mathrm{V})}$ & ++ & +++ & ++ & ++ \\
\hline HB-RPC & $V_{d c} \geq 2 \sqrt{2} U_{x o(\mathrm{~V} / \mathrm{V})}$ & + & ++ & ++ & ++ \\
\hline MRPC & $V_{d c} \geq \sqrt{2} U_{x o(\mathrm{~V} / \mathrm{V})} / k$ & ++++ & ++++ & ++++ & ++++ \\
\hline Co-HRPC & $V_{d c} \leq \sqrt{2} U_{x o(\mathrm{~V} / \mathrm{V})}$ & +++ & +++ & +++ & +++ \\
\hline HB-MMC4 RPC & $V_{d c} \geq \sqrt{2} U_{x o(\mathrm{~V} / \mathrm{V})}$ & +++++ & +++++ & +++++ & +++++ \\
\hline HB-MMC3 RPC & $V_{d c} \geq \sqrt{2} U_{x o(\mathrm{~V} / \mathrm{V})}$ & ++++ & +++++ & ++++ & ++++ \\
\hline HB-MMC2 RPC & $V_{d c} \geq 2 \sqrt{2} U_{x o(\mathrm{~V} / \mathrm{V})}$ & +++ & ++++ & +++ & +++ \\
\hline FB-MMC2 RPC & - & ++++ & +++ & ++++ & ++++ \\
\hline \multicolumn{6}{|c|}{ Scott power transformer } \\
\hline FB-RPC & $V_{d c} \geq \sqrt{2} U_{x o(\text { Scott })}$ & +++ & +++ & +++ & +++ \\
\hline TW-RPC & $V_{d c} \geq 2 U_{x o(\mathrm{Scott})}$ & ++ & +++ & ++++ & ++++ \\
\hline HB-RPC & $V_{d c} \geq 4 U_{x o(\mathrm{Scott})}$ & + & ++ & +++ & +++ \\
\hline MRPC & $V_{d c} \geq \sqrt{2} U_{x o(\text { Scott })} / k$ & ++++ & ++++ & ++++ & +++++ \\
\hline Co-HRPC & $V_{d c} \leq \sqrt{2} U_{x o(\mathrm{Scott})}$ & +++ & +++ & +++ & +++ \\
\hline HB-MMC4 RPC & $V_{d c} \geq \sqrt{2} U_{x o(\text { Scott })}$ & +++++ & +++++ & +++++ & +++++ \\
\hline HB-MMC3 RPC & $V_{d c} \geq 2 U_{x o(\mathrm{Scott})}$ & ++++ & ++++ & +++++ & +++++ \\
\hline HB-MMC2 RPC & $V_{d c} \geq 4 U_{x o(\mathrm{Scott})}$ & +++ & +++ & ++++ & ++++ \\
\hline FB-MMC2 RPC & - & ++++ & +++++ & +++ & +++ \\
\hline
\end{tabular}

The symbol " + " reflects the quantification of the parameter.

The control complexity is the highest in the HB-MMC4 RPC due to the high number of the IGBT devices, while the control is the simplest in the HB-RPC topology due to the low number of the hardware components involved. In addition, the HB-MMC4 and HB-MMC3 RPCs have the best reliability and performance in the V/V power transformer; thus, the higher is the MMC level, the better is the performance of the RPC. In the Scott power transformer, the HB-MMC4 and FB-MMC2 RPCs have the best reliability and performance, but the choice of the HB-MMC4 will be more costly and bulky than the FB-MMC2 due to the extra hardware involved in the HB-MMC4 RPC topology; thus, considering the estimated costs of each topology and the required volume for installation, the HB-MMC3 RPC fulfills the best conditions in the V/V traction power system, whereas the FB-MMC2 RPC provides the best conditions in the co-phase Scott traction power system.

According to Tables 15-17, Figure 23 shows two radar charts to compare between the multilevel RPC topologies (HB-MMC4 RPC, HB-MMC3 RPC, HB-MMC2 RPC, and FB-MMC2 RPC) in the V/V traction power transformer (Figure 23a) and the Scott traction power transformer (Figure 23b), considering an equal number of MMC SMs or voltage levels. The presented ratios per characteristic/category, and for different RPC topologies, are proportional between each other. Therefore, any of the presented ratios, in the same characteristic/category, can be considered as a reference.

The HB-MMC3 RPC is the best topology to be used in the V/V traction power system, since it does not require an IT and relatively needs a lower number of components with lower IGBT power ratings (voltage and current ratings) compared with the HB-MMC2 and the FB-MMC2 RPC. On the other hand, the FB-MMC2 RPC is the best topology to be used in the Scott traction power system, and IT can be dispensable in the co-phase Scott power system to reduce the total costs. Accordingly, Figure 24 presents the final classification of the RPC topologies. There are topologies adopted for wider applications that can be used in the V/V or Scott traction power system and show the same performance and characteristics. On the other side, there are RPC topologies for limited applications; some of them are more appropriate in the V/V traction power system, such as the HB-MMC3 RPC, and others give a better performance in the Scott traction power system. 


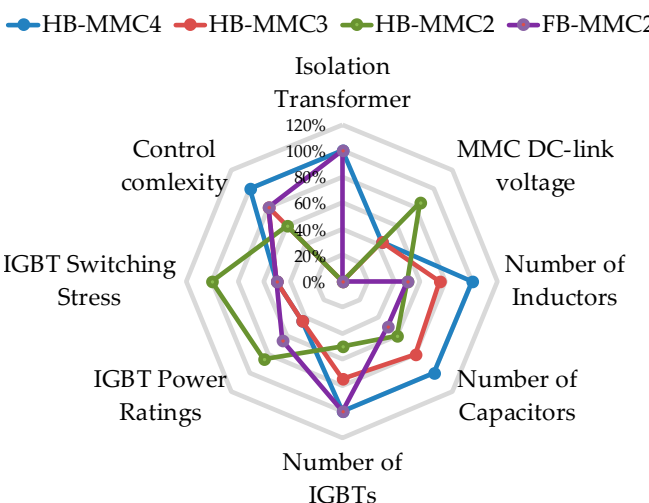

(a)

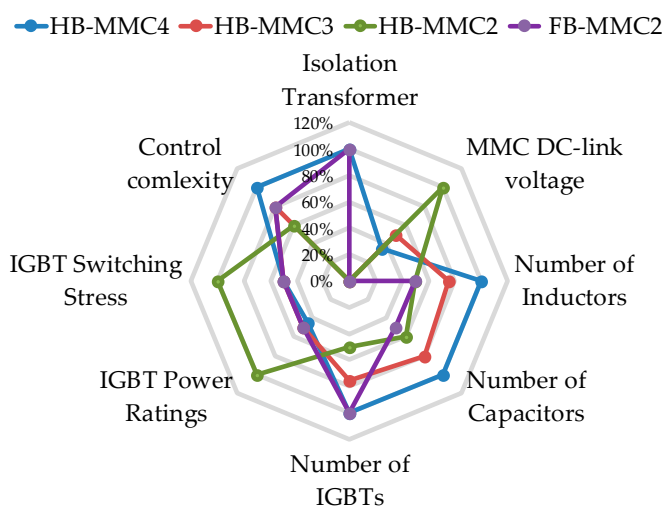

(b)

Figure 23. Comparison between the multilevel RPC topologies, using radar charts: (a) in the V/V power transformer; and (b) in the Scott power transformer (based on [6-8,10,33]).

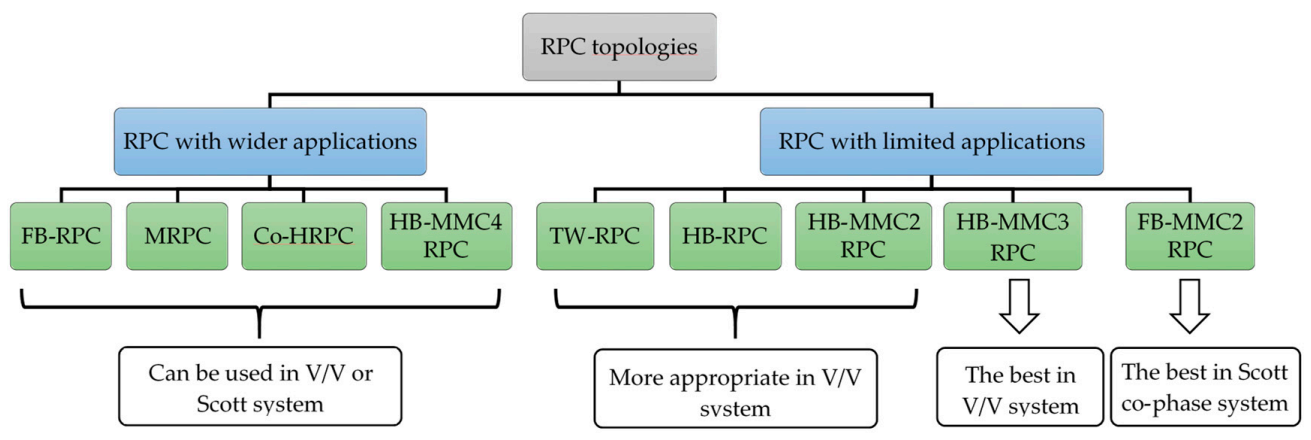

Figure 24. Final classification of the RPC topologies (based on $[6-8,10,33]$ ).

\section{Conclusions}

This paper presents the Rail Power Conditioner (RPC) operation modes and nine potential RPC topologies: RPC based on a full-bridge back-to-back two-level converter (FB-RPC); RPC based on a two-phase three-wire converter (TW-RPC); simplified RPC based on a half-bridge two-level converter (HB-RPC); modular RPC (MRPC); hybrid co-phase RPC (co-HRPC); RPC based on a full-bridge indirect modular multilevel converter (HB-MMC4 RPC); RPC based on a two-phase three-wire indirect modular multilevel converter (HB-MMC3 RPC); simplified RPC based on a half-bridge indirect modular multilevel converter (HB-MMC2 RPC); and RPC based on a direct modular multilevel converter (FB-MMC2 RPC). In this paper, after considering a similar voltage level for the multilevel RPC topologies (HB-MMC4 RPC, HB-MMC3 RPC, HB-MMC2 RPC, and FB-MMC2 RPC), the RPC topologies are evaluated and compared in terms of isolation transformer (IT) or coupling transformer (CT) requirements, number of the switching devices, power ratings of the switching devices, number of passive elements required in the RPC system (such as capacitors and inductors), RPC DC-link voltage value, estimated costs of implementation, control complexity, and the required volume for the installation.

As demonstrated, all topologies can achieve power quality improvement after compensating reactive power and overcoming the imbalance of the three-phase currents. The RPC topologies can be classified for wider applications (FB-RPC, MRPC, co-HRPC, and HB-MMC4 RPC) or limited applications (TW-RPC, HB-RPC, HB-MMC3 RPC, HB-MMC2 RPC, and FB-MMC2 RPC), where the RPC for wider applications are adapted to operate in V/V or Scott traction power systems, without high divergence in their characteristics between the V/V and Scott traction power systems. On the other hand, RPC topologies with limited applications are specified and show evident differences between the V/V and Scott traction power systems. These topologies can be more compatible to operate in either the V/V or Scott traction power system. The limited application topologies can 
give similar or better performances than the topologies with wider applications, also with a lower cost of implementation. The results confirm that the HB-MMC3 RPC is the best topology in the V/V traction power system, since it provides a similar performance of the HB-MMC4 RPC, but with a lower quantity of hardware devices, lower control complexity, and without the need for ITs, which means lower costs of implementation. On the other hand, since the reactive power compensation is not a vital factor in the Scott traction power system, the FB-MMC2 RPC is the best topology to be used in the Scott traction power system. However, ITs are required to interface between the FB-MMC2 RPC and the traction power grid, which highly increases the implementation costs of the FB-MMC2 RPC. Nevertheless, using the FB-MMC2 RPC in the co-phase Scott traction power systems helps to overcome this disadvantage, besides reducing the FB-MMC2 RPC overall costs.

Author Contributions: M.T. performed the literature review, analysis, evaluation, comprehensive comparison between the RPC topologies, and writing - original draft preparation. All authors participated in the conceptualization, methodology, and writing - review and editing. All authors have read and agreed to the published version of the manuscript.

Funding: This work was supported by the Portuguese Foundation of Science and Technology (FCT) (in Portuguese, Fundação para a Ciência e Tecnologia, within the R\&D Units Project Scope: UIDB/00319/2020). The first author Mohamed Tanta is supported by FCT Ph.D. grant with a reference PD/BD/127815/2016.

Conflicts of Interest: The authors declare no conflict of interest.

\section{Nomenclature}

$\dot{I}_{A}, \dot{I}_{B}, \dot{I}_{C}$
$i_{A}, i_{B}, i_{C}$
$\dot{I}_{L x}, \dot{I}_{L y}$
$i_{L x}, \dot{i}_{L y}$
$\dot{I}_{r x}, \dot{I}_{r y}$
$i_{r x}, i_{r y}$
$i_{r x 1}, i_{r y 1}$
$\dot{I}_{x}, \dot{I}_{y}, \dot{I}_{z}$
$i_{x}, i_{y}, i_{z}$
$\dot{U}_{x}, \dot{U}_{y}$
$\dot{U}_{x y}$
$\dot{U}_{A}, \dot{U}_{B}, \dot{U}_{C}$
$\dot{U}_{A C}, \dot{U}_{B C}$
$\dot{U}_{L x}, \dot{U}_{L y}$
$\dot{U}_{x o}(\mathrm{~V} / \mathrm{V}), \dot{U}_{x o}($ Scott $)$
$u_{x}, u_{y}$
$V_{d c}$
$V_{d c k}$
$V_{s m}$
$f_{i s w}$
$k$
$L$
$N$
$N-1$
$Z_{x}, Z_{y}, Z_{L}$

Phasors of the phase A, phase B and phase C currents phase $\mathrm{A}$, phase $\mathrm{B}$ and phase $\mathrm{C}$ instantaneous currents Phasors of the traction feeder currents

Traction feeders instantaneous currents Phasors of the compensation currents synthesized by RPC Phase $x$ and phase $y$ instantaneous compensation currents synthesized by the RPC Phase $x$ and phase $y$ instantaneous compensation currents synthesized by the $\mathrm{RPC}$ at the secondary windings of the coupling transformers Phasors of the three phase currents at the secondary windings of the V/V or the Scott power transformer Three phase instantaneous currents at the secondary windings of the V/V or the Scott power transformer

Phasors of the traction feeders line to phase voltages

Phasor of the traction feeders line to line voltage

Phasors of the three phase power grid line to phase voltages

Phasors of the three phase power grid line to line voltages

Phasors of the voltages across the RPC buffer inductors

RPC phase $x$ output voltage in V/V and Scott power transformers

Phase $x$ and phase $y$ instantaneous traction feeder voltages

DC link voltage of the RPC system

DC link voltage of one RPC module.

DC link voltage of the SM

IGBT switching frequency

Number of the RPC modules

Buffer inductor in the RPC system

MMC voltage level

Number of SM in one MMC arm

Catenary section lumped impedance 


\section{References}

1. Uzuka, T. Faster than a Speeding Bullet: An Overview of Japanese High-Speed Rail Technology and Electrification. IEEE Electrif. Mag. 2013, 1, 11-20. [CrossRef]

2. Gazafrudi, S.M.M.; Langerudy, A.T.; Fuchs, E.F.; Al-Haddad, K. Power Quality Issues in Railway Electrification: A Comprehensive Perspective. IEEE Trans. Ind. Electron. 2015, 62, 3081-3090. [CrossRef]

3. He, Z.; Zheng, Z.; Hu, H. Power Quality in High-Speed Railway Systems. Int. J. Rail Transp. 2016, 4, 71-97. [CrossRef]

4. Tanta, M.; Monteiro, V.; Sousa, T.J.C.; Martins, A.P.; Carvalho, A.S.; Afonso, J.L. Power quality Phenomena in Electrified Railways: Conventional and New Trends in Power Quality Improvement toward Public Power Systems. In Proceedings of the 2018 International Young Engineers Forum (YEF-ECE), Costa da Caparica, Portugal, 4 May 2018; pp. 25-30.

5. Morimoto, H.; Ando, M.; Mochinaga, Y.; Kato, T.; Yoshizawa, J.; Gomi, T.; Miyashita, T.; Funahashi, S.; Nishitoba, M.; Oozeki, S. Development of railway static power conditioner used at substation for Shinkansen. In Proceedings of the Proceedings of the Power Conversion Conference-Osaka 2002 (Cat. No.02TH8579), Osaka, Japan, 2-5 April 2002; Volume 3, pp. 1108-1111.

6. Luo, A.; Wu, C.; Shen, J.; Shuai, Z.; Ma, F. Railway Static Power Conditioners for High-Speed Train Traction Power Supply Systems Using Three-phase V/V Transformers. IEEE Trans. Power Electron. 2011, 26, 2844-2856. [CrossRef]

7. Wu, C.; Luo, A.; Shen, J.; Ma, F.J.; Peng, S. A Negative Sequence Compensation Method Based on a Two-Phase Three-Wire Converter for a High-Speed Railway Traction Power Supply System. IEEE Trans. Power Electron. 2012, 27, 706-717. [CrossRef]

8. Ma, F.; Luo, A.; Xu, X.; Xiao, H.; Wu, C.; Wang, W. A Simplified Power Conditioner Based on Half-Bridge Converter for High-Speed Railway System. IEEE Trans. Ind. Electron. 2013, 60, 728-738. [CrossRef]

9. Uzuka, T.; Ikedo, S.; Ueda, K. A static voltage fluctuation compensator for AC electric railway. In Proceedings of the 2004 IEEE 35th Annual Power Electronics Specialists Conference (IEEE Cat. No.04CH37551), Aachen, Germany, 20-25 June 2004; Volume 3, pp. 1869-1873.

10. Xu, Q.; Ma, F.; He, Z.; Chen, Y.; Guerrero, J.M.; Luo, A.; Li, Y.; Yue, Y. Analysis and Comparison of Modular Railway Power Conditioner for High-Speed Railway Traction System. IEEE Trans. Power Electron. 2017, 32, 6031-6048. [CrossRef]

11. Cui, G.; Luo, L.; Liang, C.; Hu, S.; Li, Y.; Cao, Y.; Xie, B.; Xu, J.; Zhang, Z.; Liu, Y.; et al. Supercapacitor Integrated Railway Static Power Conditioner for Regenerative Braking Energy Recycling and Power Quality Improvement of High-Speed Railway System. IEEE Trans. Transp. Electrif. 2019, 5, 702-714. [CrossRef]

12. Bozorgi, A.M.; Chayjani, M.S.; Nejad, R.M.; Monfared, M. Improved Grid Voltage Sensorless Control Strategy for Railway Power Conditioners. IET Power Electron. 2015, 8, 2454-2461. [CrossRef]

13. Ronanki, D.; Williamson, S.S. Modular Multilevel Converters for Transportation Electrification: Challenges and Opportunities. IEEE Trans. Transp. Electrif. 2018, 4, 399-407. [CrossRef]

14. Shu, Z.; Xie, S.; Li, Q. Single-Phase Back-To-Back Converter for Active Power Balancing, Reactive Power Compensation, and Harmonic Filtering in Traction Power System. IEEE Trans. Power Electron. 2011, 26, 334-343. [CrossRef]

15. Song, S.; Liu, J.; Ouyang, S.; Chen, X. A Modular Multilevel Converter Based Railway Power Conditioner for Power Balance and Harmonic Compensation in Scott Railway Traction System. In Proceedings of the 2016 IEEE 8th International Power Electronics and Motion Control Conference (IPEMC-ECCE Asia), Hefei, China, 22-26 May 2016; pp. 2412-2416.

16. Ma, F.; He, Z.; Xu, Q.; Luo, A.; Zhou, L.; Li, M. Multilevel Power Conditioner and its Model Predictive Control for Railway Traction System. IEEE Trans. Ind. Electron. 2016, 63, 7275-7285. [CrossRef]

17. Dai, N.Y.; Lao, K.; Lam, C. Hybrid Railway Power Conditioner with Partial Compensation for Converter Rating Reduction. IEEE Trans. Ind. Appl. 2015, 51, 4130-4138. [CrossRef]

18. Lao, K.W.; Wong, M.C.; Dai, N.; Wong, C.K.; Lam, C.S. A Systematic Approach to Hybrid Railway Power Conditioner Design with Harmonic Compensation for High-Speed Railway. IEEE Trans. Ind. Electron. 2015, 62, 930-942. [CrossRef]

19. Hu, S.; Zhang, Z.; Li, Y.; Luo, L.; Luo, P.; Cao, Y.; Chen, Y.; Zhou, G.; Wu, B.; Rehtanz, C. A New Railway Power Flow Control System Coupled with Asymmetric Double LC Branches. IEEE Trans. Power Electron. 2015, 30, 5484-5498. [CrossRef] 
20. Lao, K.; Wong, M.; Dai, N.; Lam, C.; Wang, L.; Wong, C. Analysis of the Effects of Operation Voltage Range in Flexible DC Control on Railway HPQC Compensation Capability in High-Speed Co-Phase Railway Power. IEEE Trans. Power Electron. 2018, 33, 1760-1774. [CrossRef]

21. Chen, B.; Zhang, C.; Zeng, W.; Tian, C.; Yuan, J. An electrical-magnetic hybrid power quality compensation strategy for V/V traction power supply system. In Proceedings of the 2014 IEEE Energy Conversion Congress and Exposition (ECCE), Pittsburgh, PA, USA, 14-18 September 2014; pp. 3774-3779.

22. Lao, K.-W.; Wong, M.-C.; Dai, N.Y.; Wong, C.-K.; Lam, C.-S. Analysis of DC-Link Operation Voltage of a Hybrid Railway Power Quality Conditioner and Its PQ Compensation Capability in High-Speed Cophase Traction Power Supply. IEEE Trans. Power Electron. 2016, 31, 1643-1656. [CrossRef]

23. Hu, S.; Zhang, Z.; Chen, Y.; Zhou, G.; Li, Y.; Luo, L.; Cao, Y.; Xie, B.; Chen, X.; Wu, B.; et al. A New Integrated Hybrid Power Quality Control System for Electrical Railway. IEEE Trans. Ind. Electron. 2015, 62, 6222-6232. [CrossRef]

24. Kaleybar, H.J.; Kojabadi, H.M.; Brenna, M.; Foiadelli, F.; Fazel, S.S. A two-phase three-wire quasi-Z-source based railway power quality compensator for AC rail networks. In Proceedings of the 2017 IEEE International Conference on Environment and Electrical Engineering and 2017 IEEE Industrial and Commercial Power Systems Europe (EEEIC/I CPS Europe), Milan, Italy, 6-9 June 2017; pp. 1-6.

25. Roudsari, H.M.; Jalilian, A.; Jamali, S. A Z-source railway static power conditioner for power quality improvement. In Proceedings of the 2016 7th Power Electronics and Drive Systems Technologies Conference (PEDSTC), Tehran, Iran, 16-18 February 2016; pp. 261-267.

26. Sun, Z.; Jiang, X.; Zhu, D.; Zhang, G. A novel active power quality compensator topology for electrified railway. IEEE Trans. Power Electron. 2004, 19, 1036-1042. [CrossRef]

27. Tanta, M.; Pinto, J.G.; Monteiro, V.; Martins, A.P.; de Carvalho, A.T.; Afonso, J.L. A Comprehensive Comparison of Rail Power Conditioners Based on Two-level Converters and a V/V Power Transformer in Railway Traction Power Systems. In Proceedings of the 7th Transport Research Arena (TRA 2018), Vienna, Austria, 16-19 April 2018; pp. 1-10.

28. Langerudy, A.T.; Mariscotti, A.; Abolhassani, M.A. Power Quality Conditioning in Railway Electrification: A Comparative Study. IEEE Trans. Veh. Technol. 2017, 66, 6653-6662. [CrossRef]

29. Tanta, M.; Afonso, J.A.; Martins, A.P.; Carvalho, A.S.; Afonso, J.L. Comprehensive Study for a Rail Power Conditioner Based on a Single-Phase Full-Bridge Back-to-Back Indirect Modular Multilevel Converter. In Proceedings of the Transactions on Engineering Technologies; Ao, S.-I., Gelman, L., Kim, H.K., Eds.; Springer: Singapore, 2019; pp. 263-279.

30. Yuan, J.; Xiao, F.; Zhang, C.; Ni, Z.; Zhong, Y. A hybrid negative current compensation system for high-speed railway power system. In Proceedings of the 2018 IEEE Applied Power Electronics Conference and Exposition (APEC), San Antonio, TX, USA, 4-8 March 2018; pp. 1461-1466.

31. Tanta, M.; Monteiro, V.; Exposto, B.; Pinto, J.G.; Martins, A.P.; Carvalho, A.S.; Meléndez, A.A.N.; Afonso, J.L. Simplified Rail Power Conditioner Based on a Half-Bridge Indirect AC/DC/AC Modular Multilevel Converter and a V/V Power Transformer. In Proceedings of the IECON 2017-43rd Annual Conference of the IEEE Industrial Electronics Society, Beijing, China, 29 October-1 November 2017; pp. 6431-6436.

32. Liu, L.; Dai, N. Hybrid Railway Power Conditioner Based on Half-Bridge Modular Multilevel Converter. In Proceedings of the 2016 IEEE Energy Conversion Congress and Exposition (ECCE), Milwaukee, WI, USA, 18-22 September 2016; pp. 1-7.

33. Ma, F.; Xu, Q.; He, Z.; Tu, C.; Shuai, Z.; Luo, A.; Li, Y. A Railway Traction Power Conditioner Using Modular Multilevel Converter and Its Control Strategy for High-Speed Railway System. IEEE Trans. Transp. Electrif. 2016, 2, 96-109. [CrossRef]

34. Antonopoulos, A.; Svensson, J.R. Evaluation of negative-sequence-current compensators for high-speed electric railways. In Proceedings of the 2016 IEEE Energy Conversion Congress and Exposition (ECCE), Milwaukee, WI, USA, 18-22 September 2016; pp. 1-8.

35. Hu, S.; Li, S.; Li, Y.; Krause, O.; Zare, F. A Comprehensive Study for the Power Flow Controller Used in Railway Power Systems. IEEE Trans. Ind. Electron. 2018, 65, 6032-6043. [CrossRef]

36. Shu, Z.; Xie, S.; Lu, K.; Zhao, Y.; Nan, X.; Qiu, D.; Zhou, F.; Gao, S.; Li, Q. Digital Detection, Control, and Distribution System for Co-Phase Traction Power Supply Application. IEEE Trans. Ind. Electron. 2013, 60, 1831-1839. [CrossRef] 
37. Xie, B.; Li, Y.; Zhang, Z.; Hu, S.; Zhang, Z.; Luo, L.; Cao, Y.; Zhou, F.; Luo, R.; Long, L. A Compensation System for Cophase High-Speed Electric Railways by Reactive Power Generation of SHC SAC. IEEE Trans. Ind. Electron. 2018, 65, 2956-2966. [CrossRef]

38. Ma, F.; Wang, X.; Deng, L.; Zhu, Z.; Xu, Q.; Xie, N. Multi-Port Railway Power Conditioner and Its Management Control Strategy with Renewable Energy Access. IEEE J. Emerg. Sel. Top. Power Electron. 2019, 1. [CrossRef]

39. Horita, Y.; Morishima, N.; Kai, M.; Onishi, M.; Masui, T.; Noguchi, M. Single-phase STATCOM for feeding system of Tokaido Shinkansen. In Proceedings of the 2010 International Power Electronics Conference-ECCE ASIA, Sapporo, Japan, 21-24 June 2010; pp. 2165-2170.

40. Oso, H.; Kaneko, T.; Suzuki, A. Railway Static Power Conditioner for Shin-Kurobe Substation of Hokuriku Shinkansen. Fuji Electr. Rev. 2015, 61, 52-57.

41. Tamai, S. Novel power electronics application in traction power supply system in Japan. In Proceedings of the 2014 16th International Power Electronics and Motion Control Conference and Exposition, Antalya, Turkey, 21-24 September 2014; pp. 701-706.

42. Aoki, K.; Kikuchi, K.; Seya, M.; Kato, T. Power Interchange System for Reuse of Regenerative Electric Power. Hitachi Rev. 2018, 67, 71-75.

43. Zhang, D.; Zhang, Z.; Wang, W.; Yang, Y. Negative Sequence Current Optimizing Control Based on Railway Static Power Conditioner in V/V Traction Power Supply System. IEEE Trans. Power Electron. 2016, 31, 200-212. [CrossRef]

44. Railway Static Power Conditioner | AC power feeding system for railways | MEIDENSHA CORPORATION. Available online: https://www.meidensha.com/products/railwaysystem/prod_01/prod_01_01/prod_01_01_ 03/index.html (accessed on 15 April 2020).

45. Ohmi, M.; Yoshii, Y. Validation of Railway Static Power Conditioner in Tohoku Shinkansen on Actual Operation. In Proceedings of the 2010 International Power Electronics Conference-ECCE ASIA, Sapporo, Japan, 21-24 June 2010; pp. 2160-2164.

46. Roudsari, H.M.; Jalilian, A.; Jamali, S. Flexible Fractional Compensating Mode for Railway Static Power Conditioner in a v/v Traction Power Supply System. IEEE Trans. Ind. Electron. 2018, 65, 7963-7974. [CrossRef]

47. Feng, J.; Chu, W.Q.; Zhang, Z.; Zhu, Z.Q. Power Electronic Transformer-Based Railway Traction Systems: Challenges and Opportunities. IEEE J. Emerg. Sel. Top. Power Electron. 2017, 5, 1237-1253. [CrossRef]

48. Pinto, J.G.; Tanta, M.; Monteiro, V.; Barros, L.A.M.; Afonso, J.L. Active Power Conditioner Based on a Voltage Source Converter for Harmonics and Negative Sequence Components Compensation in Electrified Railway Systems. In Proceedings of the 7th Transport Research Arena (TRA 2018), Vienna, Austria, 2018; pp. 1-10.

49. Lao, K.W.; Wong, M.C.; Santoso, S. Recent Advances of FACTS Devices for Power Quality Compensation in Railway Traction Power Supply. In Proceedings of the 2018 IEEE/PES Transmission and Distribution Conference and Exposition (T\&D), Denver, CO, USA, 16-19 April 2018; pp. 1-5.

50. Dai, N.; Wong, M.; Lao, K.; Wong, C. Modelling and control of a railway power conditioner in co-phase traction power system under partial compensation. IET Power Electron. 2014, 7, 1044-1054. [CrossRef]

51. Chang, F.; Yang, Z.; Lin, F. Research on Control Strategy of AC-DC-AC Substation Based on Modular Multilevel Converter. Math. Probl. Eng. 2017, 2017, 4157165. [CrossRef]

52. Krastev, I.; Tricoli, P.; Hillmansen, S.; Chen, M. Future of Electric Railways: Advanced Electrification Systems with Static Converters for AC Railways. IEEE Electrif. Mag. 2016, 4, 6-14. [CrossRef]

53. Kouro, S.; Malinowski, M.; Gopakumar, K.; Pou, J.; Franquelo, L.G.; Wu, B.; Rodriguez, J.; Pérez, M.A.; Leon, J.I. Recent Advances and Industrial Applications of Multilevel Converters. IEEE Trans. Ind. Electron. 2010, 57, 2553-2580. [CrossRef]

54. Lu, M.; Hu, J.; Zeng, R.; He, Z. Fundamental-Frequency Reactive Circulating Current Injection for Capacitor Voltage Balancing in Hybrid-MMC HVDC Systems During Riding Through PTG Faults. IEEE Trans. Power Deliv. 2018, 33, 1348-1357. [CrossRef]

55. Tanta, M.; Pinto, G.; Monteiro, V.; Martins, A.P.; Carvalho, A.S.; Afonso, J.L. Deadbeat Predictive Current Control for Circulating Currents Reduction in a Modular Multilevel Converter Based Rail Power Conditioner. Appl. Sci. 2020, 10, 1849. [CrossRef]

56. Deng, F.; Chen, Z. A Control Method for Voltage Balancing in Modular Multilevel Converters. IEEE Trans. Power Electron. 2014, 29, 66-76. [CrossRef] 
57. Tanta, M.; Monteiro, V.; Pinto, J.G.; Martins, A.P.; Carvalho, A.S.; Afonso, J.L. Efficiency and Cost Estimation for a Static Frequency Converter and a Rail Power Conditioner Based on an Indirect Modular Multilevel Converter in Railways Applications. In Proceedings of the ICEE International Conference on Energy and Environment: Bringing Together Engineering and Economics, Porto, Portugal; 2017; pp. 313-319.

58. Tanta, M.; Pinto, G.; Monteiro, V.; Martins, A.P.; Carvalho, A.S.; Afonso, J.L. Cost Estimation of Rail Power Conditioner Topologies based on Indirect Modular Multilevel Converter in v/v and Scott Power Transformers. In Proceedings of the 4th International Conference on Energy and Environment: bringing together Engineering and Economics, Guimarães, Portugal, 16-17 May 2019; pp. 365-370.

59. Barros, L.A.M.; Tanta, M.; Martins, A.P.; Afonso, J.L.; Pinto, J.G. STATCOM Evaluation in Electrified Railway Using v/v and Scott Power Transformers. In Proceedings of the Sustainable Energy for Smart Cities; Afonso, J.L., Monteiro, V., Pinto, J.G., Eds.; Springer International Publishing: Cham, Switzerland, 2020; pp. 18-32.

(C) 2020 by the authors. Licensee MDPI, Basel, Switzerland. This article is an open access article distributed under the terms and conditions of the Creative Commons Attribution (CC BY) license (http://creativecommons.org/licenses/by/4.0/). 